\title{
Health Information Technology and Patient Outcomes: The Role of Information and Labor Coordination
}

\author{
Jeffrey S. McCullough* Stephen T. Parente ${ }^{\dagger} \quad$ Robert Town ${ }^{\ddagger}$
}

January 6, 2016

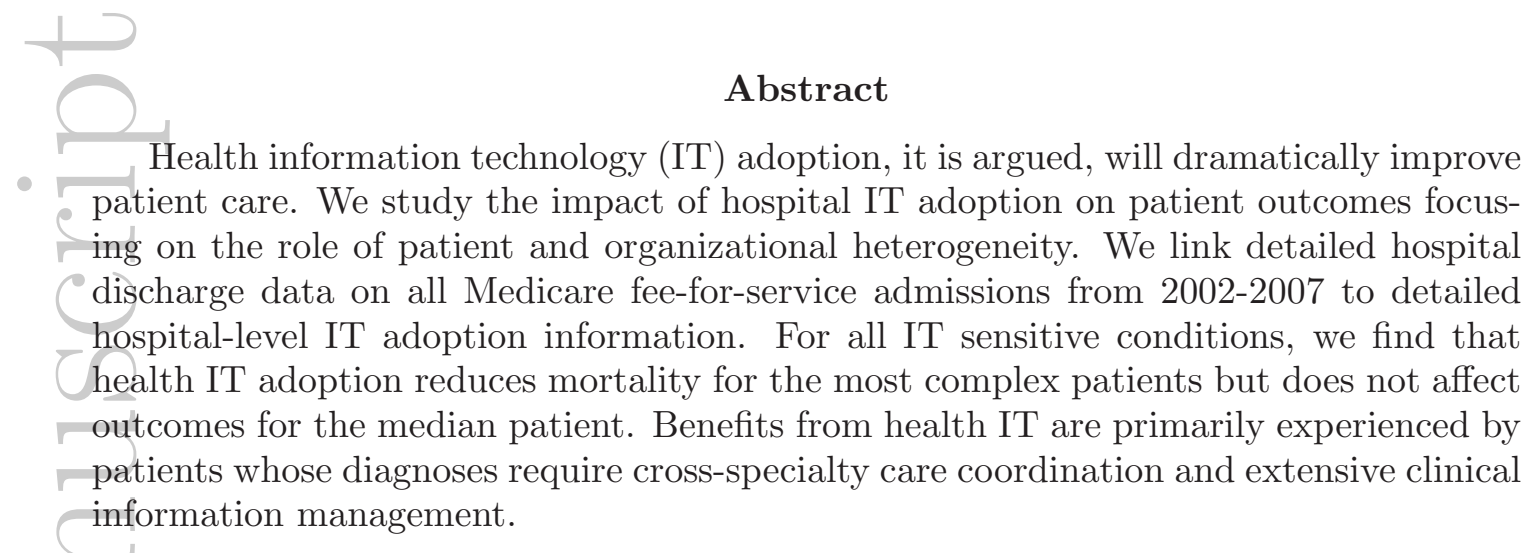

Keywords: Hospitals, Information Technology, Mortality

JEL Classification: D24, I12

We gratefully acknowledge assistance from The Robert Wood Johnson Foundation's Changes in Health Care Financing \& Organization (Grant no. 64845) and the Agency for Health Research and Quality. We have received helpful comments from David Dranove, Leila Agha, seminar participants at the University of Southern California, Ohio State University, the American Health Economics Conference, and the NBER Summer Institute. We also thank the Health Information Management Systems Society (HIMSS) Analytics for use of their data and the Minnesota Supercomputing Institute (MSI) for computing resources. The views expressed herein are those of the authors and do not necessarily reflect the views of the National Bureau of Economic Research.

\footnotetext{
*University of Minnesota, mccu0056@umn.edu
}

†The Carlson School of Management, University of Minnesota, stephen.parente@gmail.com

†The Wharton School, University of Pennsylvania and NBER, rjxtown@gmail.com

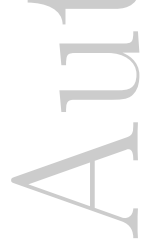




\section{Introduction}

The US health care system is often criticized as fragmented and uncoordinated. The consequences of this poorly integrated system are stark, leading to a large number of preventable medical errors and wasteful resource allocation. The cost of medical errors are famously large with some estimates attributing over 44,000 deaths annually to inpatient hospital errors (IOM, 1999). Faced with a health care system that appears far from optimized many health policy analysts have placed health information technology (IT) at the center of their reform initiatives (IOM, 1999, 2001; Buntin et al., 2011) 1] Recent improvements in health IT and the growth of IT investments in other sectors of the economy suggest that health IT can dramatically improve the practice of medicine. The recent HITECH Act (2009) commits an estimated $\$ 34$ billion in subsidies for private health care providers to adopt and utilize health IT. Although health IT's potential is clear, these technologies are not without their critics and the ultimate economic and clinical impact of widespread health IT adoption remains uncertain $2: 3$

We analyze the impact of hospitals' adoptions of different types of health IT on outcomes for millions of Medicare patients. Our data span a period of rapid IT adoption. The volume, quality and detail of our data allow us to examine heterogeneity in IT's impact across organizational and patient domains which, in turn, helps illuminate mechanisms through which health IT acts.

This study contributes to a growing economic literature on the value and impact of IT. Information technologies have reduced the costs of coordinating production, communication, and information processing, leading to a substantial increase in productivity in a wide variety of industries and settings (Stiroh, 2002; Brynjolfsson and Hitt, 2003). Information technology's benefits are not, however, evenly distributed across organizations as the gains from these technologies depend upon both organizational and labor complementarities (Brynjolfsson and Hitt, 2002). For example, Bartel et al. (2007) found that IT-enabled man-

\footnotetext{
${ }^{1}$ In his January 3, 2009 radio address, President Obama stated, "We will update and computerize our health care system to cut red tape, prevent medical mistakes, and help reduce health care costs by billions of dollars each year"

${ }^{2}$ Black et al. (2011), for example, review the literature and suggest that the IT and quality relationship is unclear.

${ }^{3}$ There are many acronyms in this article therefore provide an acronym dictionary in the appendix.
} 
ufacturing equipment increased productivity, dramatically increased product customization, and increased machine operator skill levels. Bloom et al. (2012b) found that US-based firms operating in the UK earned higher returns from IT investments than other firms. These high returns were a consequence of US firms' organizational structures that complemented IT investments. Garicano and Heaton (2010) found that the impact of police department IT adoption complements particular organizational and management practices. Similarly, Autor et al. (1998) uncovered strong evidence of skill-biased IT and labor complementarity. Other studies emphasized the role of task-level complementarities between IT and labor inputs (Baker and Hubbard, 2003; Autor et al., 2003; Acemoglu and Autor,, 2011; Bloom et al., 2012a).

Health care is an interesting environment for studying the roles of organizational and task-based complementarities in IT. Each patient's diagnoses presents its own set of information challenges. Some diagnoses require extensive information management whereas others need cross-provider care coordination. In addition, guideline adherence and medical order communications are commonly noted barriers to good quality hospital care. Health IT, it is argued, is an effective vehicle to reduce the barriers to high quality care by capturing, managing, analyzing, and disseminating this information.

Electronic Medical Records (EMRs) provide the foundation for health information systems. EMRs systematically collect patients' health information replacing traditional medical charts. Computerized provider order entry (CPOE) allows providers to electronically enter orders for services and medications. Through direct order entry, CPOE reduces opportunities for miscommunication between disparate care providers. These technologies also serve as a platform for decision support functions which may reduce prescribing errors and improve clinical guideline compliance. Our analysis primarily (but not exclusively) focuses on these core clinical applications.

Health IT's value may depend on the organizational context, how organizations apply the technology, and the information content of tasks for which the technology is used. EMR systems may automate standardized treatment guidelines and implement rules-based procedures to prevent common errors. This combination of technological and organizational capabilities is commonly referred to as "Meaningful Use" - these guideline mechanisms are emphasized in both the policy and informatics literatures. If this aspect of health IT is 
important, then adoption should improve outcomes across the general inpatient population. Health IT might also facilitate complex decision-making and communications. In particular, health IT may help address difficult clinical data management problems. Health IT might also reduce care coordination costs for patients being treated by multiple clinical specialties where communication between providers can be particularly salient and in practice is often suboptimal. If these aspects of IT are important, then adoption should improve outcomes for patients facing difficult communication and/or information management problems.

We acquire detailed, hospital-level, health IT adoption information from the Health Information Management System Society (HIMSS) Analytics for a near census of US hospitals from 2002-2007, a period of rapid technology diffusion. These data are merged with hospital organization and location information from the American Hospital Association. The number of hospitals adopting EMR increased from $16 \%$ to $33 \%$ whereas CPOE increased from $1 \%$ to over $16 \%$ over this period. We merge the IT adoption data to inpatient discharge records on every Medicare fee-for-service (FFS) patient admitted for one of four high-mortality conditions we study - acute myocardial infarction (AMI), congestive heart failure (CHF), coronary atherosclerosis (CA), and pneumonia. We view AMI as a "control" diagnoses for these analyses, capturing time varying changes to hospital quality initiatives that may be correlated with IT adoption. Although health IT may affect some aspects of AMI treatment, the most crucial steps involve limited interaction with health information systems as the diagnostic and treatment protocols require rapid execution with limited time. As we discuss in some detail below, this is especially true for AMI patients with otherwise uncomplicated ST-elevated myocardial infarctions (STEMIs).

The discharge data contain detailed information on patients' diagnoses, demographics, and outcomes. We use these data to construct patient severity measures. Patient severity is then decomposed into components that capture the information management and coordination requirements resulting from each patient's diagnoses. Decomposing these information and coordination requirements allows us a deep look into the mechanisms though which IT affects the clinical production process. We use a difference-in-differences identification strategy to remove time invariant, unobserved hospital heterogeneity that may be correlated with both health IT adoption and patient outcomes 4

\footnotetext{
${ }^{4}$ Our estimates indicate that the bias from this type of endogeneity is modest - a result that is consistent
} 
We find that health IT does not impact outcomes for patients with mean severity. We then explore whether this null finding is the result of uncontrolled differences in hospitals' use of IT (as measured by Meaningful Use) or the adoption of complementary technologies. Neither the adoption of complimentary technologies nor complying with Meaningful Use standards affect patient outcomes. These results imply that automated treatment guidelines and rules-based decision support systems have limited clinical benefits for the outcomes and conditions of the average patient.

However, the null finding on the adoption of health IT for the average patient hides considerable heterogeneity across patients. We find that IT's impact is increasing in patient severity, significantly reduces mortality for the highest-risk patients for all conditions except our control condition, AMI. These effects are precisely estimated and robust to multiple refutation tests. We also explore potential complementarities between health IT and clinical labor coordination at a patient level. We find strong evidence that IT adoption reduces mortality for those pneumonia patients requiring more care coordination and those with greater information management requirements. Information management effects dominate for CA and CHF. Finally, health IT adoption reduces AMI mortality for patients whose comorbidities require care coordination across multiple specialties. Accounting for this heterogeneous response, our estimates imply that across our IT sensitive diagnoses, mortality falls by a modest 200 deaths per 100,000 admissions after a hospital adopts both EMR and CPOE. These benefits skew towards larger hospitals with a more severe case mix. Again, these results are robust to numerous robustness and falsification tests.

The detail in our data allows us to address several other longstanding questions on the impact of IT adoption. In other contexts, network externalities have been found to affect technology adoption directly through interoperable technologies and indirectly through learning spillovers. One potential justification for the federal government promoting health IT adoption is the presence of network externalities. Any network effects in hospital IT adoption are almost surely local as health care is, in general, locally delivered. We test for such spillovers by estimating the impact of neighboring hospitals' IT adoptions on patient outcomes controlling for unobservable and time-invariant hospital heterogeneity. We find no evidence for network externalities in hospital IT adoption. The literature also emphasizes with McCullough et al. (2010) and Agha (2014). 
the role of technological improvements which may deter adoption of current technologies as organizations delay adoption waiting for better technologies to become available as well as the importance of organizational learning following IT adoption. We find no evidence that the later adoption leads to better mean outcomes or of meaningful IT learning effects.

The role of health IT is the focus of a large literature that principally relies on pre-post designs from the adoption by large, academic medical centers. In general, these studies find a large impact of IT adoption 5 However, these large effects have not been found in the more modest number of econometric analyses estimating the impact of health IT across a large number of hospitals. Our work is most closely related to McCullough et al. (2010), Agha (2014) and Miller and Tucker (2011). McCullough et al. (2010) and Agha (2014) estimate the impact of IT adoption using a hospital-level panel where the principle dependent variables are process quality and mortality respectively. They find that IT has little or no impact on average hospital quality. Miller and Tucker (2011) link birth certificate records to countylevel health IT adoption rates and find that increased health IT penetration is associated with a modest but meaningful decline in infant mortality rates.6 Dranove et al. (2012) find considerable heterogeneity in the impact of health IT adoption on hospital cost structure. The relative contribution of our work is our focus on the heterogeneous responses across patients and organizations to IT adoption. Importantly, we provide direct evidence on the underlying mechanisms through which health IT impacts patient outcomes.

The remainder of the article is organized as follows. The next section discusses the contextual background of health IT and describes in detail the mechanisms through which health IT can impact patient outcomes. Section 3 describes the data and the adoption patterns and summary statistics are presented in Section 4. Section 5 presents our results and Section 6 concludes.

\section{Background and Mechanisms}

Widespread clinical automation has only occurred during the past decade although hospitals have employed IT since the 1960s (Borzekowski, 2002). EMRs are the foundation of these

\footnotetext{
5 Buntin et al 2011) provides a recent review of this large literature.

Athey and Stern (2002) provide an early study of IT and health quality, they found that Enhanced 911 system adoption decreased both mortality and costs in emergency medicine.
}

This article is protected by copyright. All rights reserved. 
new health information systems. They replace traditional paper charts and documents a wide range of patient and diagnostic information. EMRs also capture crucial clinical data such as prescriptions and lab results. EMR adoption is, ideally, accompanied by complementary technological and organizational investments. CPOE allows providers to interact with EMR data while making decisions in real time. Providers may use CPOE to view patient information and place medical orders.

Health information systems vary in their functionality and use. Complementary applications may extend the effective reach of EMR and CPOE, facilitating communication across disparate components of a care team. Two important applications are the electronic medication administration records (eMAR) and picture archiving communications systems (PACS). The eMAR helps close-the-loop in medication ordering and dispensing by connecting pharmacists, who fill prescriptions, to nurses, who administer prescriptions, at the patient's bedside 7 Similarly, PACS facilitates communications with radiologists, potentially increasing the speed and quality of radiology consultations 8

Health IT may improve clinical quality through a variety of mechanisms. These technologies may be used to automate routine, rules-based, clinical processes. Treatment guidelines may be embedded within health information systems. These protocols use patient-level EMR data to prompt providers with suggestions or raise flags regarding potentially risky interventions. These effects should be largest for patients facing common, standardized problems that conform to well-accepted care guidelines; furthermore, these effects should be critically dependent on the sophistication and use of health IT (Jha et al., 2009; Buntin et al., 2010). This form of direct clinical decision support is, arguably, the most emphasized mechanism in the health informatics and policy literature. Furthermore, the adoption and utilization of clinical decision support systems form the key requirements for federal subsidies under the 2009 HITECH Act.

\footnotetext{
${ }^{7}$ Many additional technologies are used with prescription pharmaceuticals such as e-prescribing, designated pharmacy systems, automated dispensing, etc. We focus on EMR, CPOE, and eMAR as they are major investments and there was limited variation in the diffusion of other technologies during our study period (e.g., automated dispensing remained rare but pharmacy management systems were widely diffused prior to our study period).

${ }^{8}$ Note that we do not emphasize the Clinical Decision Support measure in the HIMSS Analytics data due to instability in the questionnaire during the survey's early years.
} 
Health IT might also impact outcomes in complicated cases that do not conform to standardized care guidelines. Many severely ill patients require extensive monitoring and testing. Health IT might improve information management and treatment quality. Similarly, complex patients may require care from a wide range of clinical specialists that may not regularly coordinate. These mechanisms are similar to those described by Autor et al. (2003). They find that IT substituted for labor involving rules-based tasks and complemented labor involving complex communication and decision making 9 Hospitals are an excellent environment for studying IT complementarities as these information problems vary across patients' diagnoses.

\section{Clinical Decision Support}

Health IT may be used to provide direct clinical decision support. National provider organizations have developed treatment protocols for a wide range of common conditions with widely accepted standards of care. These rules-based protocols may be incorporated into a hospital's EMR and CPOE applications. The most common forms of decision support are treatment guideline automation and prescribing error checks.

Treatment guidelines recommend a set of care processes for patients with common diagnoses. Guidelines may recommend a series of tests and medications to improve diagnosis and treatment. Surgical patients, for example, are at high risk for both infections and blood clots (i.e., deep vein thrombosis). Problems that may be prevented through the administration of antibiotics and heparin respectively. Decision support systems could, for example, prompt physicians to prescribe these drugs for surgical patients. Decision support systems may also be used to prevent prescribing errors. Common errors include prescribing multiple drugs with adverse interactions, drugs for which patients have a known allergy, and drug dosing errors 10 Decision support systems may automatically check for known drug-drug interactions or allergies recorded in a patient's EMR. Although physicians may deviate from these protocols with good reason, automated decision support systems may prevent random errors which, according to the IOM (1999, 2001), are quite common.

\footnotetext{
${ }^{9}$ This literature might suggest that rules-based decision support systems would also have important implications for the cost of health care delivery. These systems might, for example, standardize pharmacy and radiology order processing.

${ }^{10}$ Dosing errors are more common in children, but also occur in adult populations.
} 
Organizational and technological complements may be critical to achieving decision support effects. Decision support benefits from the adoption of EMR and CPOE along with the automation of care protocols. Furthermore, providers must enter orders electronically (e.g., electronic prescribing) to be influenced by these support systems - this could also be seen as a labor or effort input made by the organization. The benefits of these support systems are most likely to be realized by patients of moderate to low complexity. Standardized treatment guidelines are rarely implemented for complex combinations of diagnoses Boyd et al. (2005) 11 Although, it is possible that the benefits from error reduction increase with patient severity.

\section{Information Management and Care Coordination}

Health IT may support clinical information management and care coordination. Many conditions require extensive monitoring and testing, generating large quantities of clinical information. Health IT may be used to capture and organize these data, thus expediting and improving treatment decisions. For example, renal failure changes a wide range of fluid and electrolyte levels. Providers must monitor and adjust these levels on an ongoing basis. For other conditions, monitoring of respiration and cardiac function may be crucial. Based on our discussions with physicians, we identify five conditions that require extensive information management: renal failure, diabetes, hypotension, sepsis, and hypoxia. Treatment for each of these conditions require monitoring of fluid, electrolyte, and/or oxygen levels. Furthermore, they involve a variety of lab tests. The monitoring process for each of these conditions generates a large volume of data that must be repeatedly evaluated by providers.

Care coordination and communication may be facilitated by health IT. Many patients suffer from multiple conditions requiring treatment from a number of different clinical specialists. Most specialists treat a large number of patients in both inpatient and outpatient settings making regular communication costly. Physicians may also lack detailed knowledge of their colleagues' care plans. Health IT may reduce coordination and communication costs, providing physicians with easy access to their colleagues' treatment decisions.

We explore the roles of information management and coordination effects by allowing

\footnotetext{
${ }^{11}$ Patients with numerous and severe comorbidities often require drug combinations that would not be used in typical patients.
}

This article is protected by copyright. All rights reserved. 
the impact of health IT adoption to differ based on the set patient diagnoses. Information management effects would lead to higher health IT benefits for patients with monitoringintensive diagnoses. Similarly, care coordination effects would result in the benefits from health IT increasing in the number of clinical specialties. The construction of these measures is further described in the data and methods sections below.

\section{Diagnosis-Specific Effects}

In the next section we describe the diagnoses we study in greater detail. However, for the purposes of validating our identification strategy we note that one of the conditions we analyze, AMI, serves as an interesting control condition. Similar to the other conditions we study, AMI is a common condition with widely accepted diagnostic and treatment guidelines.

However, these guidelines are learned by rote and implemented rapidly (Steg et al., 2004; ACA/AHA, 2004). Thus treatments with the highest marginal product for AMI occur with little opportunity for interaction with EMR systems. This is particularly true for emergent ST-elevated myocardial infarctions (STEMIs) - a more severe type of AMI where rapid repercussion therapy is the standard of care. Naturally, AMI patients may gain some benefits from health IT after initial stabilization, these benefits should be larger for patients with secondary diagnoses of CA or CHF and for patients whose diagnoses require coordination with other clinical specialties. Thus, we distinguish between emergent STEMI patients without secondary diagnoses for CA and CHF (which we denote as STEMI) from other AMI patients (who are often ST-elevated but have other complications that are more sensitive to health IT). The effect of health IT on AMI outcomes should be lower than for other conditions. In effect, AMI patients, especially otherwise uncomplicated STEMI patients, serve as an indirect test for the validity of our identification strategy.

\section{Data}

We combine detailed hospital IT adoption data with detailed hospital- and patient-level information from 2002-2007. Hospital IT data are drawn from the HIMSS Analytics database and the 2007 American Hospital Association's (AHA) Health IT Supplement. These data are combined with the AHA's annual survey, and the MEDPAR 100\% inpatient Medicare 
claims data (2002-2007). Earlier years of these data, 1998-2001, are used for some robustness tests. We employ the 5\% Medicare Standard Analytic file of physician claims for 2007-2008.

The MEDPAR data provide detailed patient-level information for approximately 45 million aged Medicare beneficiaries with inpatient admissions. These data capture patient demographics, diagnoses, severity metrics, and outcomes. Patient-level severity and outcome measures are crucial for separating heterogeneity in clinical risk from the effects of health IT. Furthermore, these measures are important for discerning the mechanisms through which health IT affects outcomes. We employ three primary quality measures, sixty-day all-cause mortality, thirty-day readmissions (conditional upon survival), and length of stay. Other mertality and readmission durations are explored in robustness tests.

We focus on four high-frequency and high-severity primary diagnoses: acute myocardial infarction (AMI), congestive heart failure ( $\mathrm{CHF})$, coronary atherosclerosis $(\mathrm{CA})$ and pneumonia. These conditions were selected as they are common, mortality is a frequent outcome, and health IT can plausibly improve quality. We identify these patients using the primary International Statistical Classification of Diseases version 9-CM (ICD-9-CM) listed in the MEDPAR record.

CHF (ICD-9-CM: 480-486 and 487.0) is a condition in which the heart can no longer pump enough blood to the rest of the body. It is the most common diagnoses for the Medicare population. Inpatient treatment can involve surgery or medical interventions. CA (ICD-9CM: 414.0, 414.1, 414.8, 414.9) is often treated by open heart surgery in which arteries or veins from elsewhere are grafted to coronary arteries to bypass atherosclerotic narrowing and improve blood supply. Patients generally spend 4 to 5 days recovering from the surgery in which the medical staff administer several different drugs and monitor patient's fluid buildup and pneumonia symptoms. Pneumonia (ICD-9-CM: 480-486, 487.0) is a lung infection where treatment requires prompt blood culture testing to determine the type of bacteria and the administration of the appropriate antibiotics. Acute myocardial infarction, commonly called a heart attack, results from the interruption of blood supply to a part of the heart, causing heart cells to die. AMI (ICD-9-CM: 410.0-410.9) is the leading cause of death in the US. Treatment can include drug therapy, percutaneous coronary interventions or coronary artery bypass grafts. As discussed in the previous section, ST-elevated AMIs (excepting ICD-9-CM 410.7 and 410.9) without secondary CHF or CA diagnoses are likely to be less impacted by 
IT adoption and we cull them from the AMI sample for separate analysis. Sample sizes range from 945,380 admissions for AMI to 2,476,543 for CHF. Of the AMI admissions, we have 35,077 STEMIs observations.

The MEDPAR data do not contain significant detail on physicians' identities. To measure care coordination requirements (discussed in greater detail below) we turn to the Medicare Standard Analytic physician claims data for 2007-2008. These data contain claims submitted by physicians caring for patients during an inpatient episode. We use these data to identify the physician's primary specialty which we then use to calculate the expected number of unique clinical specialties treating each patient.

The HIMSS Analytics data describe hospitals' adoption and use of numerous health IT applications. We focus on CPOE and EMR, although we explore the role of other technologies such as eMAR and PACS. The HIMSS Analytics data describe each application's adoption date and whether it is in use rather than being installed.

The HIMSS Analytics data are a large national panel that reflects the health IT inventory of US hospitals. In 2007 and earlier, the database did not include all small rural institutions, specifically Critical Access Hospitals (CAHs). As such, the approximately 4,000 hospitals profiled in the HIMSS Analytics database used in this study form a near census of acute care, non-federal, non-CAH hospital providers during the study period. This sample is remarkably stable across our study period. We matched more than $95 \%$ of hospitals from year-to-year across our sample. This suggests that our results are representative of most types of US hospitals; however, we exclude Critical Access, veterans, psychiatric, and sub-acute hospitals.

Our data allow us to investigate a somewhat ancillary but important issue in health IT adoption: the role of network externalities from competitors' technology adoption. This exercise requires us to construct measures of neighboring hospital health IT adoption. Using the AHA latitude and longitude measures we construct distances between each hospital pair in-our data. Hospital specific markets are defined as all other hospitals within a 20-mile radius of a given hospital. The number and proportion of neighboring hospitals with EMR and CPOE at $t-1$ are calculated for each hospital-specific market and is used as the primary right-hand side variable in the network externality analysis. Although neighbors' EMR and CPOE adoption does not necessarily reflect an interoperable network it may well be correlated with the sharing of clinical data, the use of outpatient EMR systems, or skill spillovers in 
provider labor markets.

The AHA data complement the HIMSS Analytics data by capturing hospitals characteristics. Important characteristics include: adjusted admissions, bed size, service scope, payer mix, multi-hospital system membership, and ownership status.

\section{Meaningful Use Measures}

The presence of health IT does not mean a hospital is using the technology in a meaningful way. In particular, guideline automation and e-prescribing may be necessary to improve quality. To assess whether variation in IT utilization affects outcomes we construct Meaningful Use measures. We rely on the responses from 2007 AHA Annual Survey Information Technology Supplement. The HITECH Act (2009) contains provisions that will reward hospitals for the "Meaningful Use" of health IT. We construct our measure by mapping Stage I Meaningful Use criteria from the 2010 federal rule to the AHA IT supplement.

We construct and test six separate measures of Meaningful Use; however, we present two exemplar measures. The first examines the percent of 11 criteria that are fully implemented across all units. These criteria are drawn from three categories: electronic clinical documentation, computerized provider order entry for medications, and decision support 12 The second measure is the percent of prescription orders entered electronically. Other measures are not reported but use more or less restrictive sets of criteria. These alternative measures yield results similar to the above Meaningful Use variables.

Meaningful Use measures are cross-sectional and may well be endogenous. Hospitals who are unobservably better may implement and use their system in accordance with the Meaningful Use criteria. Although we do not have a fix for this potential endogeneity, we can sign the direction of the bias. According to the logic presented above, the coefficient on Meaningful Use will be upwardly biased in the presence of endogeneity.

\footnotetext{
${ }^{12}$ Electronic clinical documentation criteria require that systems capture patient demographics, capture nursing assessment, keep problem lists, generate medication lists, and produce discharge summaries. Specific decision support criteria include: drug-drug interaction alerts, drug-allergy alerts, drug-dosing supports, clinical guidelines, and clinical reminders.
}

This article is protected by copyright. All rights reserved. 


\section{Measuring Information Management and Coordination}

Health IT may be particularly valuable for managing complex clinical information. We identify five diagnoses that require extensive information management: renal failure, diabetes, hypotension, sepsis, and hypoxia. We denote these diagnoses IM conditions. These conditions require ongoing monitoring of fluid and electrolyte levels, frequent lab tests, and may require further monitoring of respiration or dialysis. Indicators for these conditions are based on the following ICD-9-CM codes: renal failure (584-586); diabetes (249-250); hypotension (458 and 796.3); sepsis including septicemia and bacteremia (038, 790.7, 995.91, and 995.92); and hypoxia (411.89, 799, and 997.01). Interviews with physicians suggest that for patients with primary diagnoses of $\mathrm{CHF}, \mathrm{CA}$, or AMI, information management problems from sepsis are concentrated among those also suffering from hypotension.

- Health IT may facilitate care coordination across providers for a given patient. Coordination difficulties are likely most acute when information is shared across physicians of different specialties. Using the Medicare Standard Analytic file we select claims for inpatient treatment and calculate the distribution of physician specialties treating each diagnosis. We then calculate the expected number of unique specialties that treat a patent with a given set of diagnoses. Let $D_{i}$ denote the vector of patient $i$ 's diagnoses where $D_{i}$ is an $n_{i} \times 1$ vector. Shares of specialist type $g$ for diagnosis $d$ are denoted by $s_{g d}$. This is the share of patients with ICD-9-CM diagnosis code $d$ with a claim from a specialist of type $g$. For patient $i, C_{i}$ is the expected number of unique specialists that will treat the patient and it is defined as:

$$
C_{i}=\frac{1}{n_{i}} \sum_{d_{i}}\left(\sum_{g} s_{g d} \sum_{l \neq d} \sum_{g \neq k} s_{g l}\right) .
$$

In constructing $C_{i}$ we assume that conditional on a given diagnoses the distribution of specialist probabilities are independent across diagnoses. This is an important assumption and a limitation of this measure.

The structure of ICD-9-CM codes provides an additional measure of clinical scope. Diagnostic codes are organized by major disease classifications (MDC). We count the distinct MDC categories spanned by a patient's diagnoses as an additional measure of patient-level clinical coordination. 


\section{Severity Adjustment}

Severity adjustment variables control for patient-level heterogeneity and allow us to explore the mechanisms through which health IT affects patient outcomes. Severity metrics are based on patients' demographics, admission type, current diagnoses, and treatment history. Demographic controls include age, gender, race, interactions between these groups and a third-order polynomial of age. Admission type indicators control for urgent, emergent, and transfer patients. Diagnostic measures include a weighted count of advanced diagnostic groups (ADGs) (Weiner, 1991), secondary diagnosis indicators (AMI, CHF, CA, PN, and diabetes), and indicators for the primary diagnosis subcategories. Primary diagnostic subcategories are based on fourth-digit ICD-9-CM codes except in the case of pneumonia where third-digit indicators are employed as it spans multiple 3-digit ICD-9-CM codes. Finally, prior treatment controls capture whether a patient has been hospitalized in the past 6-months and the weighted ADG for the most recent admission within that period.

For some specifications we collapse all severity controls into a single linear index, $s_{i j t}$ for patient $i$ at hospital $j$ at time $t$. This is accomplished by regressing outcome $Y_{i j t}$ on observable patient characteristics, $W_{i j t}$, and a vector of time indicators $\tau_{1 t}$ :

$$
Y_{i j t}=\mu+W_{i j t} \lambda_{1}+\tau_{1 t}+\nu_{i j t}
$$

Note that this equation does not include IT variables or hospital indicators as these could introduce endogeneity. Parameters are estimated by linear probability mode 13 and used to calculate severity index, $s_{i j t}=E\left[Y_{i j t} \mid W_{i j t}, \hat{\mu}, \hat{\lambda_{1}}, \hat{\tau_{1 t}}\right]$. In effect, $s_{i j t}$ is the national average mortality rate for patients with observed characteristics, $W_{i j t}$, at time $t 14$

We also use severity to normalize our metrics of information management and clinical coordination. Mortality is regressed on a vector of information management indicators $\left(M_{i j t}\right)$,

\footnotetext{
${ }^{13}$ Results are similar when using probits but we focus on LPM for computational tractability when bootstrapping standard errors.

${ }^{14}$ Severity measure and subsequent model results are nearly identical if parameters are allowed to vary across time or if parameters are estimated using only data from the first year.

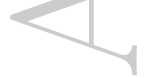

This article is protected by copyright. All rights reserved. 
$C_{i j t}, M D C_{i j t}$, and other demographic and comorbidity controls $\left(Z_{i j t}^{2}\right), 15$

$$
Y_{i j t}=\mu+Z_{i j t} \lambda_{21}+C_{i j t} \lambda_{22}+M_{i j t} \lambda_{23}+\tau_{2 t}+\nu_{i j t} .
$$

Parameters from (3) are then used to construct severity-normalized coordination $\left(s_{i j t}^{c}=\right.$ $\left.C_{i j t} \hat{\lambda}_{22}\right)$, severity-normalized information management $\left(s_{i j t}^{m}=M_{i j t} \hat{\lambda}_{23}\right)$, and other severity $\left(s_{i j t}^{o}=\hat{Y}_{i j t}-s_{i j t}^{c}-s_{i j t}^{m}\right)$. Our empirical models will be biased against finding information and coordination effects from health IT as $C_{i j t}$ and $M_{i j t}$ do not capture all diagnoses requiring clinical coordination and information management.

\section{$4 \vdash$ Empirical Strategy}

Our empirical strategy is straightforward. We estimate the impact of health IT adoption on patient outcomes for patients with different sets of diagnoses and severities. When outcomes are discrete we estimate parameters using linear probabilities models with hospital fixed effects including a rich set of patient demographics and seventy of illness controls 16 Hospital fixed effects control for time-invariant differences in hospital quality that may be correlated with IT adoption. That is, we use a difference-in-differences identification strategy relying on variation in adoption timing to identify parameters. As we document below, there is significant across-hospital variation in adoption timing.

If time-varying quality shocks are correlated with adoption, then our estimates will be biased. We employ a number of robustness checks to test the likelihood that correlated, time-varying shocks are present. We find little evidence to suggest that hospitals that adopt health IT (or do so earlier) have differential quality (either time-invariant or time-varying) than non- or late adopters. We also test the robustness of our findings to different definitions of health IT adoption and its utilization.

Much of this article's focus is devoted to estimating heterogeneous health IT effects to uncover the mechanisms through which IT impacts outcomes. We estimate those effects

\footnotetext{
${ }^{15}$ The current weighted ADG score and secondary diagnosis indicators (PN, CHF, CA, AMI) are excluded from $X_{i j t}^{2}$ because of partial multicollinearity (e.g., the ADG score is based, in part, on our information management indicators) and their conceptually ambiguous relationship to information management and clinical coordination.

${ }^{16}$ We also estimated models using probits and the results we essentially identical but we had difficulty computing standard errors for marginal effects in nonlinear specifications.
}

This article is protected by copyright. All rights reserved. 
within the models by including interactions between patient severity measures and health IT adoption. We test the robustness of these models by allowing the heterogeneity to enter flexibly. Below we provide more detail on specific models.

Base Model: We model the latent health state for patient $i$ at time $t$ within hospital $j$, $M_{i j t}^{*}$, as a function of patient and hospital characteristics. Higher values of $M_{i j t}^{*}$ correspond to poorer health. For two out of three outcomes and for the outcome that is our central focus, we do not observe $M_{i j t}^{*}$. When the outcome of interest is discrete (e.g. 60-day mortality), $M_{i j t}=1$ if $M_{i j t}^{*}>0$ and 0 otherwise. If the outcome is approximately continuous (i.e. length of stay) then $M_{i j t}=M_{i j t}^{*}$. Patient characteristics include demographic and severity measures $\left(X_{i j t}\right)$ from (2) above.

The focus here is on the impact of health IT on health. We begin by defining $T_{j t-1}$ as an indicator equal to one if a hospital has both EMR and CPOE at time $t-1$. This definition is a simplification and implicitly assumes that the adoption of these two applications represents a substantial increase in health IT. Furthermore, the lag $(t-1)$ implies that the benefits of health IT follow adoption by 1-year - these assumptions are tested in subsequent analysis.

Our base empirical specification is:

$$
M_{i j t}^{*}=\alpha_{j}+X_{i j t} \beta_{1}+T_{j t-1} \gamma_{1}+\tau_{t}+\epsilon_{i j t},
$$

where $\alpha_{j}$ is a time-invariant hospital-specific effect that may be correlated with the other right-hand side variables. In this framework, $\gamma_{1}$ measures the average change in the patient's health state resulting from health IT adoption. The term $\beta_{1}$ is a vector of parameters to be estimated, $\tau_{t}$ is a set of time indicators, and $\epsilon_{i j t}$ is an error term 17 We estimate a linear probability model using the usual linear fixed effects transformation 18 Equation 4 is estimated separately for patients with a primary diagnosis of AMI, CHF, CA, PN, and STEMI. These equations are estimated using three different outcome measures, mortality within 60-days of admission, readmission within 30-days of discharge, and length of stay.

Technological and Organizational Complementarities: Hospitals exhibit variation in both the capability and utilization of EMR systems. The returns to health IT may

\footnotetext{
${ }^{17}$ Although we do not index the error terms by equation, the error terms in each equation are unique to the equation.

${ }^{18}$ Errors are clustered by hospital to address correlation across patients within the hospital and for the same hospital across time. The errors also are heteroskedasticity robust.
}

This article is protected by copyright. All rights reserved. 
depend on complementary technological and organizational investments. In particular, rulesbased decision support systems require a sophisticated set of IT applications, automated treatment guidelines, and the use of electronic prescribing. We test whether complementary organizational inputs affect the effectiveness of health IT. Finally, using this basic framework we test for the potential role of cross-hospital spillovers or network effects in health IT adoption by including neighboring hospitals' adoption of IT as a regressor.

We utilize data from the 2007 AHA EMR supplement to measure complementary organizational inputs. We denote organizational inputs by $O_{j}$ and estimate parameters from the following equation:

$$
M_{i j t}^{*}=\alpha_{j}+X_{i j t} \beta_{3}+T_{j t-1} \gamma_{3}+O_{j} T_{j t-1} \delta_{3}+\tau_{t}+\epsilon_{i j t} .
$$

Equation 5 parameters are estimated for two alternative IT utilization measures, the first describes the percent of 11 key capabilities that facilitate decision support algorithms and the second describes the percent of pharmacy orders entered electronically. For the sake of brevity, in these and the rest of our models, mortality is the primary outcome variable.

Severity, Information Management, and Coordination: Benefits from health IT adoption may be heterogeneous across both patients and hospitals. Health IT's data collection capabilities might better capture and reduce the cost of communicating clinical information, and this information may be particularly useful for treating complex, high-severity patients. For ease of interpretation, we collapse severity adjustment variables into a single index, $s_{i j t}$, described in Equation 2. We then measure the effect of health IT allowing this effect to depend on patient severity:

$$
M_{i j t}^{*}=\alpha_{j}+X_{i j t} \beta_{4}+s_{i j t} \gamma_{4}+T_{j t-1} \delta_{4}+f\left(s_{i j t}, T_{j t-1}\right)+\tau_{t}+\epsilon_{i j t},
$$

where $\gamma_{4}, \delta_{4}$, and the function $f$ capture the effect of IT on the patient's health state and how it varies with patient severity. The function $f$ is estimated using both simple (linear) parametric and more flexible four-knot cubic spline specifications.

As discussed above, health IT can facilitate nurses' and physicians' abilities to manage, process and ultimately act upon the large amounts of information the care of complex, severely ill patients requires. Health IT may also reduce the cost of communicating information across different actors in the patient care process. Most Medicare patients are admitted 
with multiple diagnoses. Different conditions require differing amounts of information processing and care coordination. As discussed in Section 3, using Equation (3) this variation allows us to decompose patient severity into components that require information management $\left(s_{i j t}^{m}\right)$, care coordination $\left(s_{i j t}^{c}\right)$, and other factors $\left(s_{i j t}^{o}\right)$. We then estimate the parameters from the following equation to better understand the underlying mechanisms through which IT influences patient health,

$$
M_{i j t}^{*}=\alpha_{j}+X_{i j t} \beta_{5}+s_{i j t} \gamma_{5}+T_{j t-1} \delta_{5}+s_{i j t}^{m} T_{j t-1} \delta_{51}+s_{i j t}^{c} T_{j t-1} \delta_{52}+s_{i j t}^{o} T_{j t-1} \delta_{53}+\tau_{t}+\epsilon_{i j t} .
$$

The parameters $\delta_{51}, \delta_{52}$ and $\delta_{53}$ capture the impact of health IT adoption on the management of patient information, care coordination, and all other components of severity respectively. The variables $s_{i j t}, s_{i j t}^{m}, s_{i j t}^{c}$, and $s_{i j t}^{o}$ in Equations (6) and (17) are all estimated thus we need to adjust the standard errors to account for this. We block bootstrap the standard errors reestimating Equations (44) and (5) and recalculating the different $s_{i j t}$ 's in each iteration.

Learning and Innovation: Information technology and its value may evolve over time as IT manufacturers leverage improvements in computing power and reductions in the cost of data storage and invest in improving the functionality and ease of use of their systems. If innovation in these technologies is meaningful, patient benefits from IT may improve over time. Conversely, learning might increase the effective value of older information systems. We explore vintage effects of health IT adoption by letting the value of IT depend on the year of adoption. We also examine potential benefits from post-adoption learning by allowing the effect of IT to increase in the duration since adoption, either through health IT's lag structure or interactions with duration. These specifications provide simple tests of innovation and learning effects.

\section{Identification}

We identify parameters using a difference-in-differences strategy relying on variation in adoption decisions. Bloom et al. (2012b) and Miller and Tucker (2011) use a similar strategy to identify the impact of IT adoption on organizational and patient outcomes, respectively 19

\footnotetext{
19 Miller and Tucker (2011) also supplement their fixed-effects estimates with IV estimates. The IV estimates are larger in magnitude but much less precisely estimated than the fixed-effects estimates.
}

This article is protected by copyright. All rights reserved. 
This strategy is valid as long as hospital-level shocks to patient outcomes are not correlated with the IT adoption. As we discuss below, there are several threats to this identification strategy. We test and/or control for each of these threats. Ultimately, we find no evidence suggesting that hospital IT adoption is endogenous to time varying unobservables.

The first class of threats is based on the possibility that health IT investment strategies may be a function of historical trends in patient outcomes. In this scenario quality shocks precede and cause health IT adoption. If these shocks are autocorrelated then our estimates of health IT's impact would be downward biased. It is important to note that the lag between the decision to adopt an EMR and CPOE system and the actual implementation is generally several years. These systems are typically very expensive and it takes hospitals several years to plan and arrange financing 20 Thus, our priors are that this is an unlikely source of coefficient bias. Nevertheless, we test for the presence of this bias by including leads of health IT adoption in the analysis and test whether the coefficients on these leads indicate the presence of endogeneity. The results, which are discussed in greater detail below, provide no support for the contention that this model of hospital adoption behavior is relevant in our setting.

The second class of behavior that would bias our estimates is the presence of correlated, unobserved (to us), and unrelated quality investments. The adoption of health IT likely involves changes in care processes and hospitals may implement broad quality improvement initiatives that are contemporaneous to IT installation but not directly related to IT. If these quality improvement initiatives are successful then we would attribute changes in patient outcomes to IT adoption when correct attribution should be to the quality improvement initiatives. We examine the likely importance of these confounding quality improvement effects by comparing changes in outcomes for AMI and STEMI patients whose care is less likely to require provider interaction with the IT systems to other patients with the other diagnoses. In Section 2 above, we provide the clinical details that underlie this approach to dividing the AMI sample into these two types of patients. Results from these analyses (which are discussed in greater detail below) do not indicate that unobserved complementary investments explain our empirical results.

Finally, we consider the possibility that health IT adoption could unobservably alter the

\footnotetext{
${ }^{20}$ HIMSS Analytics survey results suggest that the planning stage alone takes several years.
} 
distribution of patient severity which could bias our coefficients. Health IT could alter severity measurement through coding changes and it could affect physician and patient preferences across hospitals. Severity is uncorrelated with health IT adoption for each measure we examine (See Appendix Table A5). If observed severity (which determines hospital payments) is uncorrelated with IT adoption it is likely that unobserved dimensions of severity are also unaffected by IT adoption. We also estimated models separately for elective and emergent admissions as selection based on severity should be more prevalent for elective admissions. Results were similar across admissions types.

In sum, our identification strategy is similar to that used in previous analyses of IT adoption's firm-level impact. We tested (albeit somewhat informally) for threats to this identification strategy and the evidence is consistent with our approach generating valid inference.

\section{Adoption Patterns and Summary Statistics}

Figure 1 graphs the cumulative adoption rates of different health IT systems from 1998 to 2007. Recall that our patient-level data span 2002 to 2007. At the beginning of our data only $16 \%$ of hospitals had installed an EMR and $1 \%$ of hospitals had acquired a CPOE system. eMAR system were almost never present in 2002. By the end of the sample, approximately $33 \%$ of hospitals had adopted an EMR, 28\% had installed an eMAR, 17\% had acquired a CPOE system, and 10\% had installed both an EMR and CPOE.

Basic patient-level summary statistics by primary diagnosis are presented in Table 1. Not surprisingly, the sample is predominately white and elderly with the mean age between 75 and 80 years old depending on the primary diagnosis. The average patient in our sample is quite ill and this can been seen in several of the variables. Across the diagnoses, weighted ADGs are between 4.5 and 6.2. The average number of expected specialists these patients see based on their diagnoses is over three for all conditions. Although the typical patient is quite ill, there are large variations in the severity of illness across patients for all primary diagnoses.

Given that the average patient patient in our sample is very sick, it's not surprising that outcomes for three of the five primary diagnoses are poor. Ignoring CA, 60-day mortality 
rates range from $16 \%$ for pneumonia and CHF to $36 \%$ for STEMI. The mortality rate for CA is a much more modest 3.6\%. The typical length of stay is between 4.5 and 6 days with large variation across patients. Readmissions are common, $22 \%$ of CHF patients are readmitted within 30 days and $15 \%$ of pneumonia patents are readmitted in 30-days. Readmission rates for other diagnoses fall between those extremes.

Tables 2 and 3 present mean patient and hospital characteristics by hospitals' final IT adoption status. Patient characteristics of adopters and non-adopters are very similar with few exceptions. There is little evidence that patents are sorting to adopting and non-adopting hospitals based on observable severity measures. Interestingly, there is virtually no difference in mean mortality, readmission or length of stay between adopters and non-adopters. However, hospitals that adopt health IT are notably different from non-adopters. Adopters are, on average, slightly larger, more likely to be nonprofit institutions, and less likely to be multi-hospital system members.

\section{Results}

Equation 4 results are reported in Table 4. We find no effect of health IT adoption on either mortality or length of stay although we do observe a very small increase in length of stay for $\mathrm{CHF}$ and a small reduction in CA readmissions. The coefficient of interest is significantly different from zero in only 2 of the 15 regressions and the magnitudes are uniformly small. The statistical insignificance does not reflect imprecise estimates; rather, parameters are precisely estimated and are extremely close to zero. The $95 \%$ confidence intervals do not include a $1 \%$ quality improvement for most estimates. In the Appendix we present results from a simple OLS model without fixed effects but control for hospital characteristics. Results from this specification are essentially identical to those in Table 4.

Table 4 results imply that the average effect of health IT adoption is near zero. Although consistent with McCullough et al. (2010) and Agha (2014) these findings differ from much of the health informatics and medical literatures (Buntin et al., 2011). Taken by themselves, these findings suggest that there is no there there for health IT and that policies designed to increase health IT diffusion will have little impact on patient outcomes. However, as we show below, the actual impact of health IT on outcomes is more subtle. We attribute differences in 
our results from the broad informatics literature to our study design. We analyze outcomes for all FFS Medicare inpatient admissions (subject to the criteria described in the Data section) and control for time-invariant hospital quality. The vast majority of studies in the informatics literature are single (or few) sites studies relying on a pre/post design and with few exceptions the literature does not address the potential endogeneity of health IT adoption.

Results presented in Table 4 are robust to alternative health IT measures. We estimate Equation 4 parameters using both more and less restrictive health IT definitions. Parameter estimates from alternative definitions do not change the basic conclusion. In Panel A of Table 5 we present results from one alternative model defining health IT adoption as having installed four major IT components: EMR, CPOE, eMAR and PACS. As in Table 4, parameter estimatès are small and not significantly different from zero implying that our null results are not a consequence of our health IT definitions.

Technological and Organizational Complementarities: Our null finding could be biased as our specifications fail to account for the role of unobserved technological and organizational inputs. In particular, Equation 4 does not measure the inputs required to implement rules-based decision support capabilities. Beyond addressing a potential omitted variables issue, understanding the role of organizational heterogeneity in technology use on its effectiveness is a longstanding question we can examine. We thus estimate the parameters in Equation (5) using a variety of alternative organizational and technological input measures. Table 5 Panel B allows the health IT adoption effect to depend on an index of Meaningful Use criteria. This index captures the use of automated treatment guidelines and related technological inputs. Similarly, Panel C results allow benefits to depend on physicians' use of electronic prescribing (i.e., the percent of pharmacy orders made electronically). We find no evidence that health IT effects depend on complementary organizational and technological inputs. This null result is robust to alternative patient outcome measures and a wide range of alternative specifications and Meaningful Use metrics.

Health IT's value could also depend on the local IT infrastructure. That is, there could be spillovers from IT labor agglomeration economies or network externalities. Ideally, patients' clinical histories would be available in an interoperable EMR system. Although such systems remain quite rare, neighboring providers' health IT adoption may generate spillovers through 
PACS systems, electronic lab result communication, or even providers' acceptance of and skill in health IT utilization. We estimate specifications that allow the effect of health IT to depend on neighboring hospitals' health IT adoption. Table 5 shows that EMR \& CPOE are not more effective when the percent of neighboring hospitals with EMR \& CPOE increase. We obtain the same result for the number of neighboring hospitals, using more flexible functions of neighboring hospitals' adoption, or using alternative outcome measures.

We also examine whether the health IT effect differs across hospital characteristics and organizational structures in Panel E. The health IT effect is independent of system membership, scale, and COTH membership. Although health system organization likely plays an important role in IT value, the impact of these characteristics are too small to observe in our data.

- Severity, Information Management and Coordination: We next explore potential heterogeneity in the impact of health IT as a function of patient seventy by estimating the Equation 6. We estimate $f$, the function that relates severity and health IT adoption to mortality, using two different approaches. First, we note that there is substantial variation in severity across patients for all of our primary diagnoses. Estimated mean mortality in the $1^{\text {st }}$ decile of $s_{i}$ is .033, .032, .000, .021, and .119 for PN, CHF, CA, AMI, and STEMI respectively. Expected mortality in the $10^{\text {th }}$ decile jumps to $.325, .339, .113, .528$, and .691 respectively 21

The first parameterization of the severity and IT relationship is a simple interaction between $T_{j t-1}$ and $s_{i j t}$. Panel A in Table 6 presents these results. Health IT has a significant mortality effect, but this is small for low-severity patients and benefits from IT adoption increase with severity. Although the parameters are difficult to interpret directly, marginal effects at mean severity are $-0.5 \%$ for $\mathrm{PN},-0.01 \%$ for CHF, $-0.01 \%$ for CA, $0.0001 \%$ for AMI, and $0.007 \%$ for STEMI. However, this linear specification is potentially restrictive. Our next model allows more flexibility in severity and its interactions with health IT. We employ a four-knot cubic spline of severity and interact this function with health IT adoption 22

Table 6. Panel B presents parameter estimates from this spline specification. Because

${ }^{21}$ Each decile measures the average outcome of the within-range patients; thus, the $10^{\text {th }}$ decile is the average outcome for patients in the $90^{t h}$ through $100^{t h}$ percentiles.

${ }^{22}$ We employe a variety of specifications and they yield similar results to those in Figure 2 . Knots are placed equally across the marginal distribution of $s$ (Harrell, 2001).

This article is protected by copyright. All rights reserved. 
the parameter estimates from semi-parametric models are difficult to interpret directly (we present them here for transparency purposes), Figure 2 graphs the marginal effects of health IT and their 95\% confidence intervals by decile of severity. Health IT has no measurable benefit for relatively healthy patients, however it significantly decreases mortality for highseverity $\mathrm{PN}, \mathrm{CHF}$, and CA patients 23 Adoption significantly decreases mortality in the $6^{\text {th }}$ decile of severity and higher for pneumonia patients and for CHF and CA patients in the highest severity decile. Qualitative work suggests that the relatively large PN effect may be due to the increased role of medical (as opposed to surgical) treatment and the important role played by lab result monitoring and nutrition coordination for high-risk patients. The AMI estimates are an order of magnitude lower than those for other conditions and not statistically significant at any severity level.

- Integrating IT adoption effects over the severity distributions corresponds to averting 0.83 deaths per hospital per year. Although the average effect is modest, adoption at hospitals with large and complex patient populations avert as many as eight deaths per year. The benefits are most notable for pneumonia and $\mathrm{CHF}$, where health IT adoption reduces 60-day mortality by 0.67 and 0.12 deaths per hospital per year respectively. These diagnoses are frequent, high-risk, and sensitive to health IT adoption. Adoption has a smaller effect on CA patients, averting 0.04 deaths per hospital per year, as this diagnosis has a much lower average mortality rate. The point estimates imply that health IT has almost no effect on aggregate AMI (-0.019) and STEMI (0.019) mortality.

Estimated mortality reductions align with the findings of Miller and Tucker (2011). They estimate that EMR adoption reduces infant mortality by approximately 13 deaths per 100,000 births and the impact of IT appears larger for low-birth weight infants. Also consistent with our results, Miller and Tucker (2011) find heterogeneous impacts of health IT 24 We examine health IT's impact on an elderly population that is severely ill with a much higher baseline mortality rate, thus our estimates should differ in magnitude.25 Across the conditions

\footnotetext{
${ }^{23}$ In nearly all specifications health IT adoption is associated with a small decrease in quality for low-risk patients. These effects are always small and usually statistically insignificant. They may, however, reflect difficulties that arise from using EMR \& CPOE systems with imperfect interface design. The effort required to use such systems could degrade average quality whereas the benefits these systems might only accrue to higher-risk patients.

${ }^{24}$ They find the impact of IT is higher for mothers with low education and income.

${ }^{25}$ Our IT sensitive measures have an average 60 -day mortality rate of $15 \%$ and the average 7 -day infant
} 
we study, we find an average mortality reduction of approximately 200 deaths per 100,000 admissions from IT adoption. The impact is largest for PN where IT adoption is estimated to prevent 500 deaths per 100,000 admissions. Health IT adoption reduces approximately 10 deaths per 100,000 admissions for both CA and CHF. Health IT's effect on AMI and STEMI mortality is approximately zero.

One concern is that health IT adoption could be correlated with other organizational and health care process changes in the hospital. That is, our estimates could be reflective of these changes and not capturing the causal impact of health IT. Our priors are that health IT should have a much smaller effect on AMI and STEMI outcomes. The lack of an effect for these patients suggests that our estimates are capturing true health IT adoption effects rather than unobserved quality improvement initiatives that may be correlated with IT investments.

- We explore the mechanisms behind IT's heterogeneous treatment effects. We do this by estimating the parameters of Equation 7 to measure the relationships between health IT and complex clinical information management and care coordination. Table 7 reports these results. As expected, each of the component severity metrics has a parameter of approximately 1. Parameter estimates for interactions between health IT and the component of severity measures are, with one exception, negative.

Parameters for $s_{i j t}^{c}$ and $s_{i j t}^{m}$ are most precisely estimated for PN patients where health IT facilitate both care coordination and information management. Expected mortality associated with care coordination is reduced by $8.8 \%$ and mortality associated with information management is reduced by $11 \%$ for PN if the hospital has adopted Health IT. Health IT has a significant effect for $\mathrm{CHF}$ and $\mathrm{CA}$ patients with information management problems. Although health IT does not affect mortality for the average AMI patient, it has striking benefits for patients whose diagnoses span other clinical specialties; essentially, health IT does not impact outcomes for the typical AMI patient, but patients do realize mortality reductions when their secondary diagnoses require coordination with other clinical specialties. Health IT has no detectable effect for STEMI patients.

For four of the five primary diagnoses, the sum of the coefficients on the health IT interactions for care coordination and information management are notably larger than the coefficient on the interaction with other factors that drive severity. That is, the estimates mortality rate is $0.5 \%$. 
point to health IT affecting high-severity patients by facilitating cross-provider communication and helping hospital staff manage clinical information. The roles that IT plays in these tasks appears to vary across primary diagnoses. Finally, these estimates likely understate information and coordination effects as $s^{o}$ certainly includes some variation based on information management and care coordination problems.

The AMI effect provides an additional identification test. AMI involves less medical management and fewer medical record (paper or electronic) interactions during the initial and critical steps of treatment, particularly for ST-elevated MIs. Health IT should have a smaller effect on AMI although it may be sensitive to other quality improvement initiatives. Health IT effects are between 5- and 20-times larger for CHF, CA, and PN than for either AMI or uncomplicated STEMIs (see Table 6). We also estimate Equations 446] using patient safety indicators (PSIs) that should not be sensitive to health IT. Health IT should not effect the rate of accidental punctures, foreign bodies left during procedures, or postoperative hip fractures. Health IT has no affect on these non-sensitive quality metrics.

These results emphasize the importance of complementarities between IT and labor inputs (Autor et al.,, 2003; Hubbard, 2003; Baker and Hubbard, 2003; Acemoglu and Autor, 2011). In particular, Autor et al. (2003) argue that IT facilitates complex coordination and problem solving tasks when used in high-skill settings. Despite the emphasis of the health informatics and health policy literatures, we find little support for the hypothesis that health IT improves quality through rules-based decision support. This may be due to the complexity of medical decision making. Clinical decisions should be especially difficult to automate. Although our results do not emphasize the role of complementary organizational inputs, other studies suggest that these issues are relevant to health IT utilization and value (McCullough and Snir, 2010; Dranove et al., 2012).

Learning and Innovation: Results from the learning model are reported in Table 8 , In Panel A we find that the value of IT does not significantly increase two-or-more years post adoption. There is some evidence of post-adoption learning in specifications where health IT is interacted with both severity and the duration since adoption. These effects are only observed for relatively high risk patients (Appendix Table A3) and continue to work through information and coordination mechanisms (Appendix Table A4). Although our basic results based on Equations 6f 7 are robust to these alternative specifications, the 
presence and magnitudes of learning effects are sensitive to specification. We find no evidence that innovation significantly change IT value over time (Panel B) 26 This small magnitude is unsurprising as the wider IT and productivity literature finds IT value grows slowly and is difficult to detect empirically (Brynjolfsson and Hitt, 2003; Stiroh, 2002). Lee et al. (2013) find that hospital IT productivity effects mirror other industries and are stable over time.

\section{Robustness}

Our ability to estimate causal relationships between IT adoption and health outcomes depends on the validity of our difference-in-differences identification strategy. For this strategy to be valid unobserved changes in hospital quality must be uncorrelated with the adoption of health IT. As noted in Section 4.1 there are several plausible scenarios under which the adoption of health IT could be correlated with shocks to hospital quality. In this section we present the results from a series of tests for these potential threats to identification.

We-begin by examining whether shocks to outcomes precede and lead to health IT investment. If health IT were adopted in response to current quality problems then leads of IT adoption (e.g., adoption at $t+1$ and especially $t+2$ ) would appear to decrease quality. We estimate models with indicators for the periods preceding IT adoption. These results are reported in Table 8 Panel C. Future adoption is uncorrelated with current quality but lagged IT adoption continues to improve quality for high-risk patients. We also estimate alternative models interacting technology adoption lead indicators with patient severity reported in Table 8 Panel D. The $t+2$ variable parameters are small and statistically insignificant, consistent with the hypothesis that IT adoption is orthogonal to hospital quality changes. The $t+1$ coefficient on the interaction between severity and IT adoption is relatively large and negative (but still insignificant) but the lagged IT effects are no longer statistically significant. However, recall that $t+1$ is the period that HIMSS Analytics records the adoption as going live and operational and we assume that it takes one year for implementation. Thus, the pattern we observe here is consistent with the implementation occurring somewhat more quickly than we assume, but does not suggest an endogeneity problem. Also, as discussed above, the estimated AMI and STEMI effects provide an additional falsification test. These

\footnotetext{
${ }^{26} \mathrm{We}$ also explore a series of related tests for innovation effects. All tests suggest that innovation effects are too small to be detected.
}

This article is protected by copyright. All rights reserved. 
results, described in Section 6 and reported in Tables 6,8, further support our identifying assumptions.

We build on these analyses by incorporating group-specific time trends and learning effects into Equations 447. Of course, if there are heterogeneous trends in hospital quality and if these trends systematically correlate with technology adoption our estimates will be biased. Ideally, we would estimate models with hospital-specific time trends (which adds over 2,800 parameters), but several of these models had difficulty converging. We instead incorporate separate linear time trends for adopters and non-adopters which provides direct evidence on the magnitude of this potential problem. In this robustness test specification we also allow for post-adoption learning by interacting all IT variables (and their interactions with our coordination and information management variables) with the duration since adoption.

- Results from these models are presented in Appendix Tables A3 and A4. Estimates from Models 45 continue to show no relationship between IT and outcomes for the mean patient 27 Consistent with our previous findings the benefits from health IT are only realized by relatively high-severity patients (Table A3) and the estimated magnitudes of these effects are similar to our estimates presented above in Table 6 Panel A in the short run. Estimates in Appendix Tables A3 also imply that the benefits of health IT increase over time for PN, CHF, and AMI; although, this result is sensitive to specification. Results based on Equation 7 are presented in Appendix Table A4. We again observe that information management and coordination effects dominate and are statistically significant for PN, CHF, CA, and AMI; although, in this version the AMI information management effect is significantly increasing in time and the coordination effect is no longer statistically significant. The short-run magnitudes of the IT effects are similar to those implied by Table 7 results. The benefits from health IT for CHF patients facing care coordination problem improve over time as do the benefits from AMI patients with information management problems. Once again, the time-varying effects of health IT are sensitive to specification.

We also explore many alternatives specifications for Equations 4 - 7 28 Adopters might

\footnotetext{
${ }^{27}$ Because of space considerations, these results are not presented here but are available from the author upon request.

${ }^{28}$ We estimate many specifications reflecting alternative hypotheses and robustness tests. The large number of regressions creates the potential for spurious correlation to appear significant on occasion. We believe this is unlikely given the consistency of results within hypotheses. However, we employ a retention sample to
} 
also differ in the ability to treat high-risk cases; consequently, we estimate Equation [6]allowing for interactions between $\alpha_{j}$ and $s_{i j t} 29$ Parameter estimates for this interacted model were very similar to those of Equation [6] and do not suggest that our linear separability assumption drives our findings.

Correlation between controls $\left(X_{i j t}\right)$ and the construction of $s_{i j t}$ could bias the standard errors of the marginal effects of $T_{t-1}$. Alternative specifications replacing $X_{i j t}$ with flexible functions of $s_{i j t}$ yielded similar results. Ultimately, the finding that health IT improves outcomes for high-severity patients is remarkably consistent across all the specifications. We also explored the implications of estimating linear probability model confirming our results using probits and logits 30

We considered a variety of alternative market definitions for our tests of cross-hospital spillovers presented in Table 5 Panel D. We emphasize markets defined by fixed radii as definitions based on patient flows have endogeneity problems and tend to be too large. Our results, however, are not sensitive to using a smaller 15-mile radius (probably appropriate for urban hospitals) or a larger definition such as hospital referral regions.

Another concern is that the value of decision support systems could increase in patient severity. Drug interactions, for example, could be more prevalent and more dangerous in patients with high-severity diagnoses. We used two approaches to explore this issue. First, we don't expect that the benefits of decision support systems to be focused on information- and coordination-dependent severity - we would expect larger parameter estimates for $(E M R \& C P O E) \times s^{o}$ for treatment conditions in Table 8 . Second, although the effects of decision support could be concentrated among patients facing information management and care coordination problems, they should still require more sophisticated technological inputs. We addressed this concern by estimating Equation 5 models (Table 5) with severity interactions. The benefits of IT did not increase with IT inputs even when interacted guard against this possibility. We first estimate Equations [4]6 for a wide range of specifications using a $20 \%$ subsample. We then confirm these findings with a separate $20 \%$ subsample and then the full sample. Results were similar across samples in each case.

$2^{29}$ We had difficulty estimating the analogous version of Equation 7 due to the number of parameters involved.

${ }^{30}$ Standard errors for the marginal effects of $T_{t-1}$ did not converge when using the delta method in some non-linear specifications.

This article is protected by copyright. All rights reserved. 
with severity.

Finally, health IT could change patients' apparent severity. Information systems could, for example, improve the documentation of comorbidities making patients treated at hospitals with health IT appear sicker. We test for this possibility by regressing severity on IT adoption conditional upon hospital and time fixed effects and hospital characteristics. We find no correlation between IT adoption and severity (Appendix Table A5).

\section{Conclusion}

We measure the effect of health IT on inpatient clinical outcomes using a difference-indifferences identification strategy and detailed patient-level data. Health IT does improve outcomès for patients with complex, high-severity, diagnoses; although, we find no relationship between IT and quality for the average patient. The total effect is modest. Health IT adoption averts 200 deaths per 100,000 admissions across the IT sensitive conditions we examine. The rate of mortality reduction would likely be lower for the entire US population as we examine relatively high-severity conditions; although, the total number of deaths averted per adoption would rise. We find no relationship between health IT and either readmissions or length of stay.

The health IT policy literature and the first-stage Meaningful Use rules emphasize the role of clinical decision support systems. These systems implement rules-based algorithms to prevent and correct clinical errors. Our results do not suggest that health IT improves quality through rules-based decision support systems. Rather, we find that health IT improves quality by facilitating coordination and communication across providers and by facilitating clinical information management. These mechanisms yield benefits for high-risk patients. These mechanisms are often overlooked in the health IT debate but play an important role in the broader IT and economics literature (Autor et al., 2003; Acemoglu and Autor, 2011). Miller and Tucker (2011) find that health IT is more effective among relatively low income and low education populations. These populations may experience higher severity and both information management and care coordination might be particularly important for these populations.

These findings may also offer an explanation regarding why economic studies of health 
IT and health outcomes (McCullough et al., 2010; Agha, 2014; Miller and Tucker, 2011) are often less optimistic than studies in the clinical and informatics literature (Hillestad et al., 2005; Buntin et al., 2011). Most studies of health IT value are performed at large academic medical centers - institutions that specialize in complex cases. The effect of health IT on quality should be higher at these institutions. These findings further suggest that the high returns from academic institutions should be difficult to duplicate at the average US hospital even with the adoption and utilization of sophisticated decision support systems.

An important limitation of our study is that our data do not include the effects of newer, potentially better, information systems. However, our results suggest a slow rate of effective innovation for health IT. More recent technologies are correlated with larger mortality reductions, but these effects are quite small and not statistically significant. This apparently slow productivity growth rate is similar to the evolution of average IT value in other industries (Stiroh, 2002; Brynjolfsson and Hitt, 2003) and of health IT on general productivity (Lee et al., 2013). Similarly, cross-hospital adoption spillovers appear to have little effect on the health IT and quality relationship. However, other studies that are more focused on the topic find evidence of cross-hospital spillovers in IT adoption behavior (Miller and Tucker, 2009; Dranove et al., 2012). Finally, we find limited evidence of post-adoption learning and these improvements are only realized for high-severity patients.

Our results should not be interpreted as measuring the consequences of Meaningful Use from the HITECH Act. Rather, we employ cross-sectional Meaningful Use data to provide evidence that our estimates are robust to health IT measurement error. The value of Meaningful Use and potentially heterogeneous consequences of clinical decision support systems merits further study.

A further limitation is that our data do not capture all of health IT's potential benefits. Information technology might enhance quality of care and the patient experience without affecting mortality, readmissions, or length of stay. We have, however, found similar results when studying patient safety indicators. Other studies using panel data techniques have found only small changes in process quality measures (McCullough et al., 2010; Jones et al., 2010) following health IT adoption. Health IT may also affect the efficiency of health care delivery systems (Borzekowski, 2010; Dranove et al., 2012; Lee et al., 2013; Agha, 2014). Health IT could affect the efficiency of care through information management and care coordination 
or through completely different mechanisms. Ultimately, our estimates likely underestimate the welfare effects from health IT adoption and largely ignore potential cost reducing benefits.

\section{References}

ACA/AHA, "ACC/AHA Guidelines for the Management of Patients With ST-Elevation Myocardial Infarction, Executive Summary," Circulation 110 (2004), 588-636.

Acemoglu, D. And D. Autor, "Skills, Tasks and Technologies: Implications for Employment and Earnings," Handbook of Labor Economics 4B (2011), 1043-1171.

AgHA, L,, "The Effects of Health Information Technology on Costs and Quality of Medical -Care," Journal of Health Economics 34 (2014), 19-30.

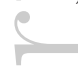

Athey, S. And S. Stern, "The Impact of Information Technology on Emergency Health Care Outcomes," RAND Journal of Economics 33 (2002), 399-432.

Autor, D., L. Katz. And A. Krueger, "Computing Inequality: Have Computers Changed the Labor Market?," Quarterly Journal of Economics 113 (1998), 1169-1213.

Autor, D., L. F. Levy And R. Murnane, "The Skill Content of Recent Technological Change: An Empirical Exploration," Quarterly Journal of Economics 118 (2003), 12791333.

Baker, G. And T. Hubbard, "Make Versus Buy in Trucking: Asset Ownership, Job Design, and Information," American Economic Review 93 (2003), 551-572.

Bartel, A., C. Ichniowski And K. Shaw, "How does information technology affect productivity? Plant-level comparisons of product innovation, process improvement, and worker skills," Quarterly Journal of Economics (2007), 1721-1758.

Black, A., J. Car, C. Pagliari, C. Anandan, K. Cresswell, T. Bokun, B. McKinstry, R. Procter, A. Majeed And A. Sheikh, "The Impact of eHealth on the Quality and Safety of Health Care: A Systematic Overview," PLos Med 8 (2011). 
Bloom, N., L. Garicano, R. Sadun and J. V. Reenen, "The Distinct Effects of Information Technology and Communication Technology on Firm Organization," Management Science 60 (2012a), 2859 - 2885.

Bloom, N., R. Sadun and J. V. Reenen, "Americans Do IT Better: U. S. Multinationals and the Productivity Miracle," American Economic Review 102 (2012b), 167-201.

Borzekowski, R., "Health Care Finance and the Early Adoption of Hospital Information Systems," Finance and Economics Discussion Series 41 (2002).

_ _ , "Measuring the Cost Impact of Hospital Information Systems: 1987-1994," Journal of Health Economics 28 (2010), 938-949.

Boyd, C., J. Darer, C. Bould, L. Fried, L. Boult and A. Wu, "Clinical Practice Guidẹlines and Quality of Care for Older Patients with Multiple Comorbid Diseases," JAMA 294 (2005), 716-724.

Brynjolfsson, E. and L. Hitt, "Computing Productivity: Firm-Level Evidence," The Review of Economics and Statistics 85 (2003), 793-808.

Brynjolfsson, T. B. E. And L. Hitt, "Information Technology, Workplace Organization, and Labor Demand," Quarterly Journal of Economics 117 (2002), 339-376.

Buntin, M., M. Burke, M. Hoaglin and D. Blumenthal, "The Benefits of Health Information Technology: A Review of the Recent Literature Shows Predominantly Positive Results," Health Affairs 30 (2011), 464-471.

Buntin, M., S. Jain and D. Blumenthal, "Health Information Technology: Laying the Infrastructure for National Health Reform," Health Affairs 29 (2010), 1214-1219.

Dranove, D., C. Forman, A. Goldfarb and S. Greenstein, "The Trillion Dollar Conundrum: Complementarities and Health Information Technology," NBER Working Paper 18281 (2012).

Garicano, L. and P. Heaton, "Information Technology, Organization, and Productivity in the Public Sector: Evidence from Police Departments," Journal of Labor Economics 28 (2010), 167-201. 
Harrell, F. E., Regression Modeling Strategies: With Applications to Linear Models, Logistic Regression, and Survival Analysis (New York: Springer, 2001).

Hillestad, R., J. Bigelow, A. Bower, F. Girosi, R. Meili, R. Scoville and R. TAYLOR, "Can electronic medical record systems transform health care? Potential health benefits, savings, and costs," Health Affairs 24 (2005), 1103-1117.

Hubbard, T., "Information, Decisions, and Productivity: On-Board Computers and Capacity Utilization in Trucking," American Economic Review 93 (2003), 1328-1353.

IOM, To Err Is Human: Building a Safer Health System (Washington, DC: National Academy Press, 1999).

- Crossing the Quality Chasm: A New Health System for the 21st Century (Washington, DC: National Academy Press, 2001).

Jha, A., C. Desroches, E. Cambell, K. Donelan, S. Rao, T. Ferris, A. Shields, S. Rosenbaum and D. Blumenthal, "Use of Electronic Health Records in U.S. Hospitals," The New England Journal of Medicine 360 (2009), 1628-1638.

Jones, S., J. Adams, E. Schneider, J. Ringel And E. McGlynn, "Electronic Health Record Adoption and Quality Improvement in US Hospitals," Health Services Research 16 (2010), SP64-SP71.

Lee, J., J. McCullough And R. Town, "The Impact of Health Information Technology on Hospital Productivity," The RAND Journal of Economics 44 (2013), 545-568.

McCullough, J., M. Casey, I. Moscovice and S. Prasad, "The Effect of Health Information Technology On Quality In US Hospitals," Health Affairs 29 (2010), 647-654.

McCullough, J. And E. Snir, "Monitoring Technology and Firm Boundaries: PhysicianHospital Integration and Technology Utilization," Journal of Health Economics 29 (2010), $457-467$.

Miller, A. And C. Tucker, "Privacy Protection and Technology Diffusion: The Case of Electronic Medical Records," Management Science 55 (2009). 
—_, "Can Health Care Information Technology Save Babies?," The Journal of Political Economy 119 (2011), 289-324.

Steg, P., R. Goldberg, J. Gore, K. Fox, K. Eagle, M. Flather, I. Sadiq, R. Kasper, S. Rushton-Mellor and F. Anderson, "Baseline characteristics, management practices, and in-hospital outcomes of patients hospitalized with acute coronary syndromes in the Global Registry of Acute Coronary Events (GRACE)," The American Journal of Cardiology 90 (2004), 358-363.

Stiroh, K., "Information Technology and the US Productivity Revival: What Do the Industry Data Say?," American Economic Review 92 (2002), 1559-1576.

WeINER, J., "Development and Application of a Population-Oriented Measure of Adjusted Care Case-Mix," Medical Care 29 (1991), 452-472.

\section{Tables and Figures}

\section{Appendix Tables}
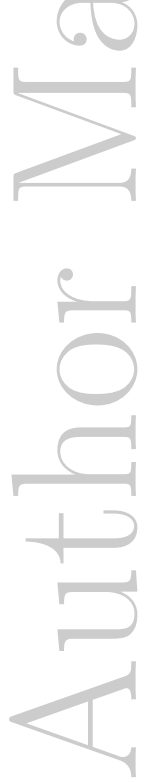
Figure 1: Diffusion of health IT applications

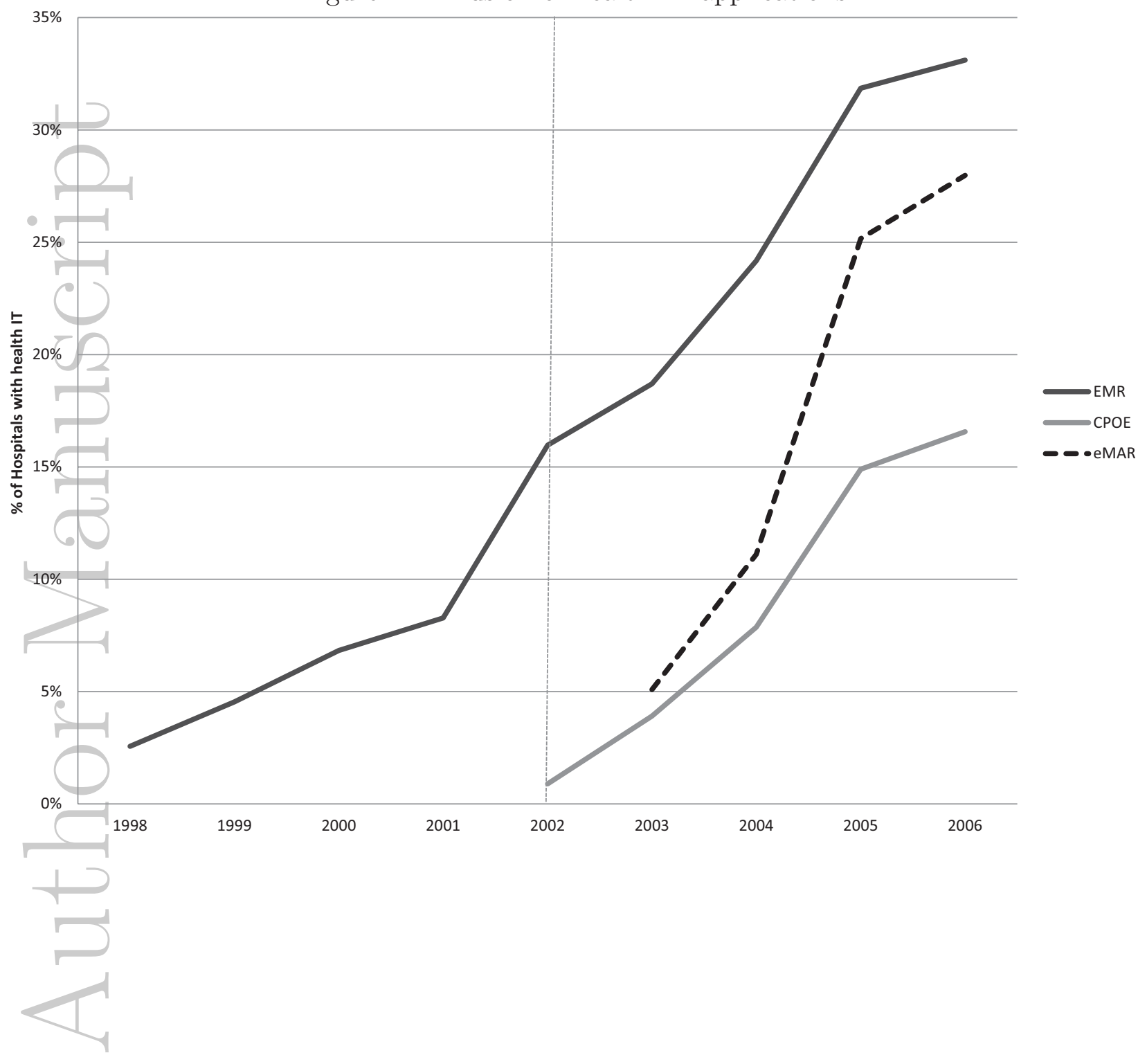

This article is protected by copyright. All rights reserved. 
Figure 2: Marginal effect of health IT on mortality by diagnosis and deciles of severity
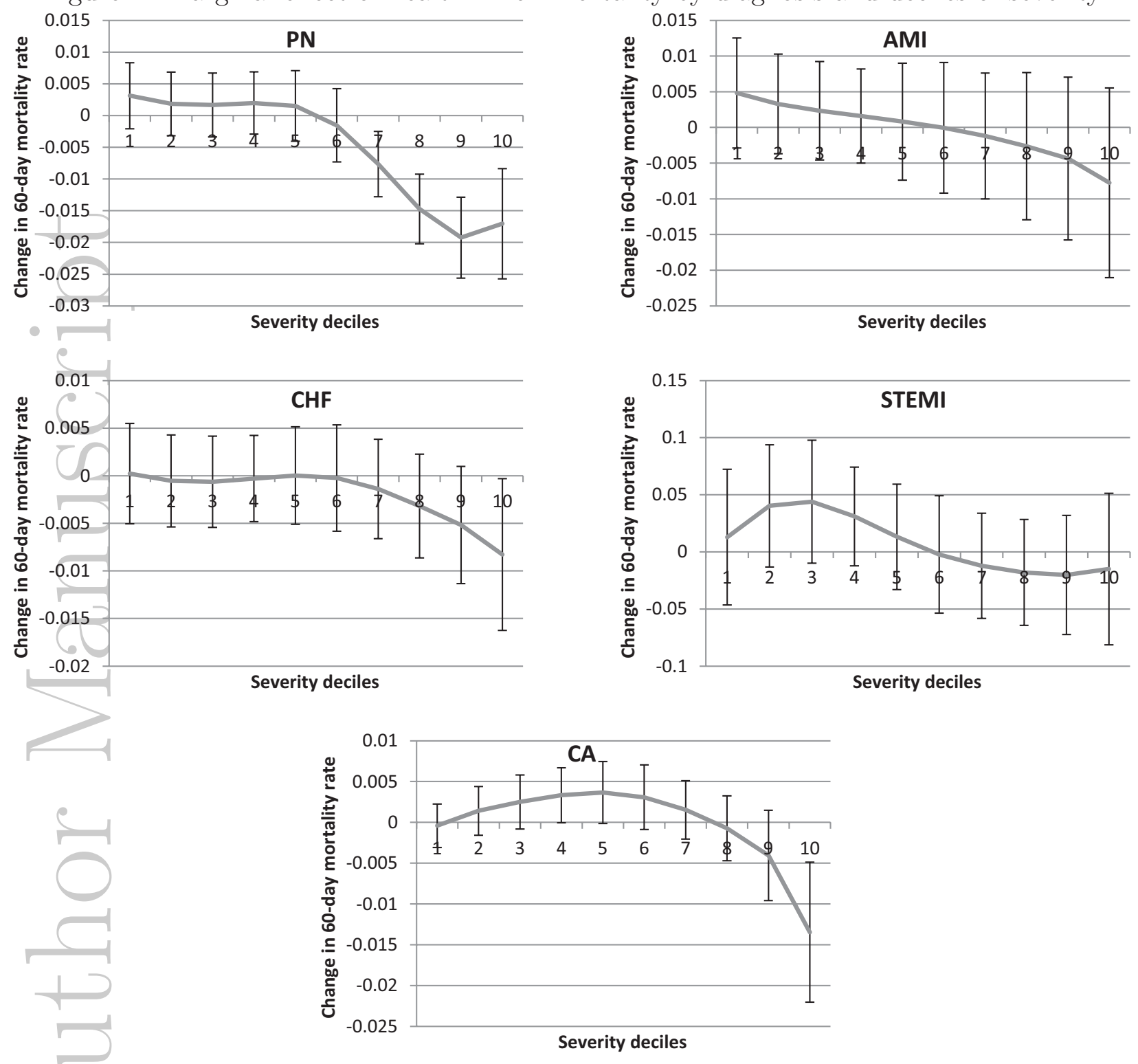

This article is protected by copyright. All rights reserved. 
Table 1: Means and (standard deviations) of patient characteristics by primary diagnosis

\begin{tabular}{lccccc}
\hline \hline Variable & PN & CHF & CA & AMI $^{\dagger}$ & STEMI $^{\ddagger}$ \\
\hline Admissions & $2,167,654$ & $2,399,648$ & $1,004,402$ & 878,547 & 35,770 \\
Female & 0.551 & 0.568 & 0.452 & 0.522 & 0.569 \\
& $(0.497)$ & $(0.495)$ & $(0.498)$ & $(0.500)$ & $(0.495)$
\end{tabular}

White

$\begin{array}{lllll}0.878 & 0.830 & 0.870 & 0.872 & 0.872\end{array}$

Age

$\begin{array}{lllll}(0.327) & (0.375) & (0.336) & (0.334) & (0.334)\end{array}$

$\begin{array}{lllll}80.00 & 79.99 & 75.77 & 79.591 & 79.522\end{array}$

\section{Weighted ADGs}

$\begin{array}{lllll}(8.402) & (8.412) \quad(7.078) & (8.429) \quad(8.628)\end{array}$

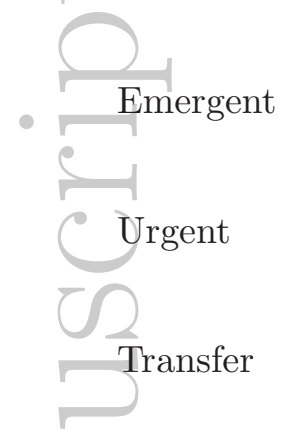

$\begin{array}{ccccc}6.16 & 5.22 & 4.54 & 4.908 & 4.619 \\ (1.858) & (1.647) & (1.565) & (1.843) & (2.189)\end{array}$

$$
(1.85
$$

0.70

(0.456)

0.703

0.492

$0.709 \quad 1.000$

0.219

(0.457)

$(0.5)$

(0.454)

(0.000)

(0.414)

0.214

0.242

$0.226 \quad 0.000$

0.03

(0.41)

(0.428)

(0.419)

(0.000)

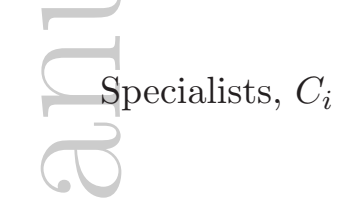

(0.181)

0.035

0.085

$0.124 \quad 0.045$

Number of MDCs

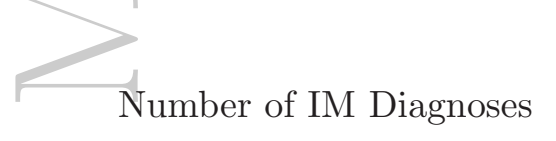

$$
3.59
$$

(0.183)

(0.279)

$(0.330) \quad(0.207)$

(0.816)

$$
3.58
$$

3.34

3.577

3.230

$$
4.25
$$

(0.76)

(0.834)

(0.770)

(0.996)

(1.281)

3.63

3.09

3.475

3.514

0.512

(1.234)

(1.161)

(1.220)

(1.406)

(0.76)

Length of Stay

Readmission, 30-day

$$
5.85
$$

0.649

0.431

0.570

0.527

(4.452)

(0.766)

(0.592)

(0.718)

(0.712)

Mortality, 60-day

$\begin{array}{ccccc}0.150 & 0.221 & 0.166 & 0.211 & 0.180 \\ (0.358) & (0.415) & (0.372) & (0.408) & (0.384)\end{array}$

r

Severity, coord. $\left(s^{c}\right)$

0.157

0.161

0.036

$0.235 \quad 0.360$

(0.364)

(0.367)

$(0.185)$

(0.424)

(0.480)

0.109

0.123

0.032

$0.1454 \quad 0.1581$

(0.033)

(0.038)

$(0.012)$

(0.044)

$(0.072)$

Severity, info. mgmt. $\left(s^{m}\right)$

$\begin{array}{ccccc}0.010 & 0.006 & 0.006 & 0.0307 & 0.0430 \\ (0.034) & (0.052) & (0.025) & (0.069) & (0.097)\end{array}$

Severity, other $\left(s^{o}\right)$

$0.038 \quad 0.032$

$0.002 \quad 0.0589 \quad 0.1591$

This article is protected by copyright. All rights reserved \begin{tabular}{lllll}
$(0.063)$ & $(0.055)$ & $(0.018)$ & $(0.100)$ & $(0.083)$ \\
\hline \hline
\end{tabular}

$\dagger$ includes non-STEMIs and STEMIs with secondary CHF or CA diagnoses.

$\ddagger$ includes STEMI without secondary diagnoses of CHF or CA. 
Table 2: Means and (standard deviations) of patient data by primary diagnosis and final hospital IT adoption status

\begin{tabular}{|c|c|c|c|c|c|c|c|c|c|}
\hline \multirow[b]{2}{*}{ Variable } & \multicolumn{2}{|c|}{ PN } & \multicolumn{2}{|c|}{$\mathrm{CHF}$} & \multicolumn{2}{|c|}{$\mathrm{CA}$} & \multicolumn{2}{|c|}{$\mathrm{AMI}^{\dagger}$} & \multirow[b]{2}{*}{ non-Ad } \\
\hline & non-Adopters & Adopters & non-Adopters & Adopters & non-Adopters & Adopters & non-Adopters & Adopters & \\
\hline Admissions & $1,942,619$ & 225,035 & $2,134,909$ & 264,739 & 88,4516 & 119,886 & 105,816 & 772,731 & \\
\hline \multirow{2}{*}{ Female } & 0.551 & 0.546 & 0.569 & 0.563 & 0.455 & 0.432 & 0.518 & 0.522 & \\
\hline & $(0.497)$ & $(0.498)$ & $(0.495)$ & $(0.496)$ & $(0.498)$ & $(0.495)$ & $(0.500)$ & $(0.499)$ & $(0.4$ \\
\hline \multirow[t]{2}{*}{ White } & 0.881 & 0.855 & 0.834 & 0.803 & 0.872 & 0.856 & 0.853 & 0.874 & \\
\hline & $(0.324)$ & $(0.353)$ & $(0.372)$ & $(0.398)$ & $(0.334)$ & $(0.351)$ & $(0.354)$ & $(0.332)$ & $(0.36$ \\
\hline \multirow{2}{*}{ Age } & 80.00 & 80.04 & 80.01 & 79.83 & 75.80 & 75.55 & 79.34 & 79.63 & \\
\hline & $(8.391)$ & $(8.492)$ & $(8.404)$ & $(8.477)$ & $(7.09)$ & $(6.983)$ & $(8.407)$ & $(8.432)$ & $(8.7:$ \\
\hline \multirow{2}{*}{ Weighted ADGs } & 6.16 & 6.17 & 5.22 & 5.24 & 4.54 & 4.52 & 4.916 & 4.906 & \\
\hline & $(1.856)$ & $(1.871)$ & $(1.646)$ & (1.658) & $(1.564)$ & $(1.573)$ & $(1.846)$ & $(1.843)$ & \\
\hline \multirow{2}{*}{ Emêrgent } & 0.700 & 0.745 & 0.699 & 0.733 & 0.493 & 0.483 & 0.707 & 0.709 & \\
\hline & $(0.458)$ & $(0.436)$ & $(0.459)$ & $(0.443)$ & $(0.5)$ & $(0.5)$ & $(0.455)$ & $(0.454)$ & $(0$. \\
\hline \multirow[t]{2}{*}{ Urgent } & 0.223 & 0.193 & 0.217 & 0.194 & 0.243 & 0.238 & 0.237 & 0.225 & \\
\hline & $(0.416)$ & $(0.394)$ & $(0.412)$ & $(0.396)$ & $(0.429)$ & $(0.426)$ & $(0.425)$ & $(0.418)$ & $(0.0$ \\
\hline \multirow{2}{*}{ Transfer } & 0.034 & 0.037 & 0.033 & 0.047 & 0.080 & 0.126 & 0.190 & 0.115 & \\
\hline & $(0.18)$ & $(0.189)$ & $(0.18)$ & $(0.211)$ & $(0.271)$ & $(0.331)$ & $(0.392)$ & $(0.319)$ & $(0.2$ \\
\hline \multirow{2}{*}{ Specialists, $C_{i}$} & 3.59 & 3.59 & 3.58 & 3.58 & 3.35 & 3.34 & 3.591 & 3.575 & \\
\hline & $(0.816)$ & $(0.817)$ & $(0.761)$ & $(0.753)$ & $(0.835)$ & $(0.827)$ & $(0.747)$ & $(0.773)$ & $(0.9$ \\
\hline \multirow{4}{*}{ IM Diagnoses } & 4.25 & 4.26 & 3.64 & 3.60 & 3.09 & 3.06 & 3.456 & 3.477 & \\
\hline & $(1.282)$ & $(1.277)$ & $(1.235)$ & $(1.226)$ & (1.163) & $(1.145)$ & $(1.205)$ & $(1.222)$ & \\
\hline & 0.512 & 0.515 & 0.648 & 0.653 & 0.430 & 0.441 & 0.570 & 0.570 & \\
\hline & $(0.76)$ & $(0.757)$ & $(0.766)$ & $(0.763)$ & $(0.592)$ & $(0.598)$ & $(0.713)$ & $(0.719)$ & $(0.7$ \\
\hline \multirow{2}{*}{ Mortality, 60-day } & 0.157 & 0.156 & 0.161 & 0.160 & 0.036 & 0.035 & 0.224 & 0.236 & \\
\hline & $(0.364)$ & $(0.363)$ & $(0.368)$ & $(0.366)$ & $(0.185)$ & $(0.184)$ & $(0.417)$ & $(0.425)$ & $(0.4$ \\
\hline \multirow{2}{*}{ Length of Stay } & 5.86 & 5.71 & 5.38 & 5.44 & 4.43 & 4.70 & 6.299 & 5.943 & 5.4 \\
\hline & $(4.443)$ & $(4.52)$ & $(4.535)$ & $(4.893)$ & $(4.635)$ & $(4.964)$ & $(5.874)$ & $(5.436)$ & $(7.09$ \\
\hline \multirow{2}{*}{ Readm., 30-day } & 0.151 & 0.148 & 0.222 & 0.217 & 0.167 & 0.157 & 0.197 & 0.212 & 0.1 \\
\hline & $(0.358)$ & $(0.355)$ & $(0.415)$ & $(0.413)$ & $(0.373)$ & $(0.364)$ & $(0.398)$ & $(0.409)$ & $(0.3$ \\
\hline
\end{tabular}

${ }^{\dagger}$ includes non-STEMIs and STEMIs with secondary CHF or CA diagnoses.

‡ includes STEMI without secondary diagnoses of CHF or CA.

This article is protected by copyright. All rights reserved. 
Table 3: Sample means and (standard deviations) of hospitals

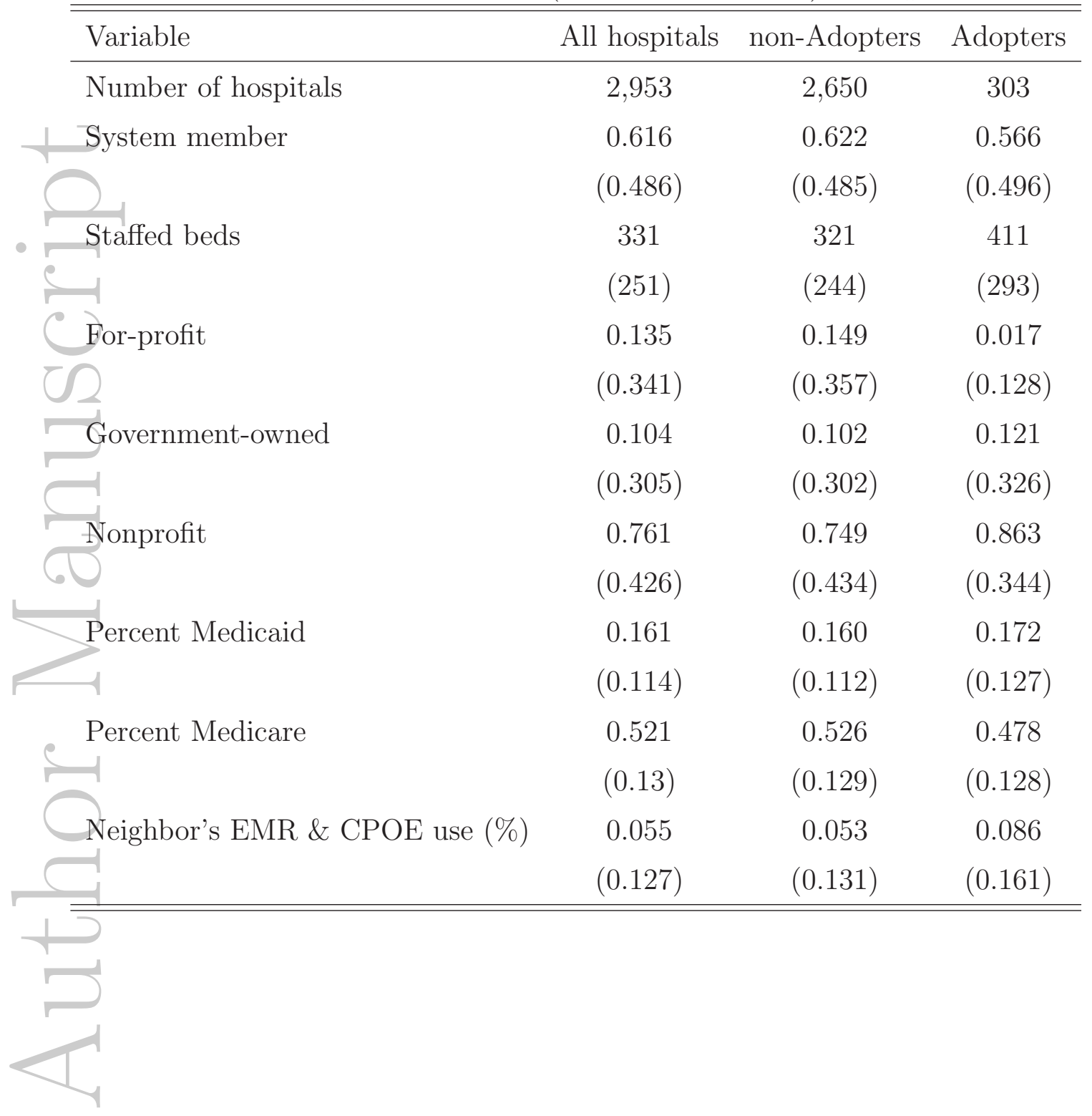

This article is protected by copyright. All rights reserved. 
Table 4: FE estimation of the impact of EMR \& CPOE on patient outcomes

\begin{tabular}{|c|c|c|c|c|c|}
\hline & $\mathrm{PN}$ & $\mathrm{CHF}$ & $\mathrm{CA}$ & $\mathrm{AMI}^{\dagger}$ & STEMI $^{\ddagger}$ \\
\hline \multicolumn{6}{|c|}{ Mortality, 60-days (A) } \\
\hline EMR \& CPOE & -0.004 & -0.001 & -0.001 & -0.0004 & 0.009 \\
\hline & $(0.002)$ & $(0.002)$ & $(0.001)$ & $(0.0003)$ & $(0.018)$ \\
\hline \multicolumn{6}{|c|}{ Length of stay (B) } \\
\hline EMR \& CPOE & 0.017 & $0.070^{*}$ & -0.115 & -0.053 & 0.263 \\
\hline & $(0.035)$ & $(0.035)$ & $(0.063)$ & $(0.061)$ & $(0.260)$ \\
\hline \multicolumn{6}{|c|}{ Readmissions, 30-days (C) } \\
\hline EMR \& CPOE & 0.000 & 0.001 & $-0.006^{* *}$ & 0.0004 & 0.004 \\
\hline & $(0.001)$ & $(0.001)$ & $(0.002)$ & $(0.003)$ & $(0.014)$ \\
\hline Observations & $2,167,654$ & $2,399,648$ & $1,004,402$ & 878,547 & 35,770 \\
\hline
\end{tabular}

†includes non-STEMIs and STEMIs with secondary CHF or CA diagnoses.

\$includes STEMI without secondary diagnoses of CHF or CA.

*Denotes significance at $p<0.05$ and $* *$ at $p<0.01$

Key parameters from 15 regressions estimated by OLS including hospital FE

and year indicators, standard errors clustered by hospital. Regressions include

demographic controls, diagnostic controls, admissions type indicators, and multi-hospital system membership. 
Table 5: FE estimates of alternative health IT measures on 60-day mortality

\begin{tabular}{|c|c|c|c|c|c|}
\hline & $\mathrm{PN}$ & $\mathrm{CHF}$ & $\mathrm{CA}$ & $\mathrm{AMI}^{\dagger}$ & STEMI ${ }^{\ddagger}$ \\
\hline \multicolumn{6}{|c|}{ Health IT application index (A) } \\
\hline \multirow[t]{2}{*}{ EMR \& CPOE \& EMAR \& PACS } & -0.006 & -0.001 & -0.001 & 0.001 & 0.054 \\
\hline & $(0.003)$ & $(0.002)$ & $(0.002$ & $(0.005)$ & $(0.025)$ \\
\hline \multicolumn{6}{|c|}{ Adoption and percent of utilization criteria met (B) } \\
\hline \multirow[t]{2}{*}{ EMR \& CPOE } & -0.001 & -0.004 & -0.003 & -0.008 & 0.054 \\
\hline & $(0.004)$ & $(0.003)$ & $(0.002)$ & $(0.006)$ & $(0.034)$ \\
\hline \multirow{2}{*}{$\begin{array}{l}(\mathrm{EMR} \& \mathrm{CPOE}) \times \\
\text { Utilization criteria met }\end{array}$} & 0.000 & 0.000 & 0.000 & 0.017 & -0.105 \\
\hline & $(0.000)$ & $(0.000)$ & $(0.000)$ & $(0.012)$ & $(0.070)$ \\
\hline \multicolumn{6}{|c|}{ Adoption and \% of pharmacy orders made electronically (C) } \\
\hline \multirow{2}{*}{ EMR \& CPOE } & 0.000 & -0.006 & -0.004 & -0.004 & 0.019 \\
\hline & $(0.004)$ & $(0.004)$ & $(0.002)$ & $(0.006)$ & $(0.032)$ \\
\hline \multirow{2}{*}{$\begin{array}{l}(\mathrm{EMR} \& \mathrm{CPOE}) \times \\
\% \text { e-pharmacy orders }\end{array}$} & 0.000 & $0.0001^{*}$ & 0.000 & 0.0001 & -0.0002 \\
\hline & $(0.000)$ & $(0.000)$ & $(0.000)$ & $(0.0001)$ & $(0.0004)$ \\
\hline \multicolumn{6}{|c|}{ Cross-hospital spillovers (D) } \\
\hline \multirow{2}{*}{ EMR \& CPOE } & -0.0037 & 0.0009 & -0.0011 & 0.002 & -0.033 \\
\hline & $(0.0028)$ & $(0.0042)$ & $(0.0016)$ & $(0.008)$ & $(0.038)$ \\
\hline \multirow[t]{2}{*}{ Neighbor's EMR \& CPOE (\%) } & 0.0004 & 0.0008 & 0.0051 & 0.003 & -0.019 \\
\hline & $(0.0048)$ & $(0.0042)$ & $(0.0030)$ & $(0.004)$ & $(0.023)$ \\
\hline \multirow{2}{*}{$\begin{array}{l}(\mathrm{EMR} \& \mathrm{CPOE}) \times \\
(\text { Neighbor's EMR \& CPOE })\end{array}$} & -0.0032 & 0.0001 & -0.0012 & -0.032 & 0.159 \\
\hline & $(0.0096)$ & $(0.0086)$ & $(0.0064)$ & $(0.019)$ & $(0.080)$ \\
\hline \multicolumn{6}{|c|}{ Health IT and hospital characteristics (E) } \\
\hline \multirow{2}{*}{$(\mathrm{EMR} \& \mathrm{CPOE})$} & -0.0045 & 0.0012 & -0.0002 & 0.0058 & 0.0520 \\
\hline & $(0.0037)$ & $(0.0036)$ & $(0.0022)$ & $(0.0059)$ & $(0.0309)$ \\
\hline \multirow{2}{*}{$(\mathrm{EMR} \& \mathrm{CPOE}) \times$ System } & $-0.0016^{*}$ & -0.0095 & 0.0000 & -0.0086 & -0.0116 \\
\hline & $(0.0040)$ & $(0.0035)$ & $(0.0024)$ & $(0.0053)$ & $(0.0324)$ \\
\hline \multirow{2}{*}{$(\mathrm{EMR} \& \mathrm{CPOE}) \times \mathrm{COTH}$} & -0.0015 & 0.0070 & -0.0001 & -0.0020 & 0.0206 \\
\hline & $(0.0052)$ & $(0.0045)$ & $(0.0028)$ & $(0.0077)$ & $(0.0408)$ \\
\hline \multirow[t]{2}{*}{$(\mathrm{EMR} \& \mathrm{CPOE}) \times$ Beds } & 0.0000 & 0.0000 & 0.0000 & 0.0000 & -0.0001 \\
\hline & $(0.0000)$ & $(0.0000)$ & $(0.0000)$ & $(0.0000)$ & $(0.0001)$ \\
\hline Observations & $2,167,654$ & $2,399,648$ & $1,004,402$ & 878,547 & 35,770 \\
\hline
\end{tabular}


Table 6: FE estimates of EMR \& CPOE adoption on 60-day mortality allowing for heterogeneous effects in patient severity

\begin{tabular}{|c|c|c|c|c|c|}
\hline & $\mathrm{PN}$ & $\mathrm{CHF}$ & $\mathrm{CA}$ & $\mathrm{AMI}^{\dagger}$ & STEMI $^{\ddagger}$ \\
\hline \multicolumn{6}{|c|}{ Health IT interacted with severity (A) } \\
\hline \multirow[t]{2}{*}{$s_{i}$} & $1.0220^{* * *}$ & $1.0195^{* * *}$ & $1.0188^{* * *}$ & $1.0165^{* * *}$ & $0.9414^{* * *}$ \\
\hline & $(0.0010)$ & $(0.0010)$ & $(0.0031)$ & $(0.0039)$ & $(0.0098)$ \\
\hline \multirow{2}{*}{ EMR \& CPOE } & $0.0085^{* *}$ & 0.0029 & $0.0043^{*}$ & $0.0069^{*}$ & 0.0500 \\
\hline & $(0.0025)$ & $(0.0021)$ & $(0.0018)$ & $(0.0038)$ & $(0.0343)$ \\
\hline \multirow{2}{*}{$(\mathrm{EMR} \& \mathrm{CPOE}) \times s_{i}$} & $-0.0854^{* * *}$ & $-0.0308^{*}$ & $-0.1436^{* *}$ & $-0.0304^{*}$ & -0.1196 \\
\hline & $(0.0153)$ & $(0.0126)$ & $(0.0440)$ & $(0.0150)$ & $(0.0737)$ \\
\hline \multicolumn{6}{|c|}{ Health IT interacted with flexible function of of severity (B) } \\
\hline \multirow{2}{*}{ EMR \& CPOE } & 0.0046 & 0.0012 & -0.0004 & 0.0054 & -0.0393 \\
\hline & $(0.0038)$ & $(0.0041)$ & $(0.0014)$ & $(0.0045)$ & $(0.0708)$ \\
\hline \multirow{2}{*}{$\operatorname{EMR} \& \mathrm{CPOE} \times f_{1}\left(s_{i}\right)$} & -0.0386 & -0.0249 & 0.2065 & -0.0252 & 0.4370 \\
\hline & $(0.0527)$ & $(0.0553)$ & $(0.1279)$ & $(0.0493)$ & $(0.4211)$ \\
\hline \multirow{2}{*}{$\mathrm{EMR} \& \mathrm{CPOE} \times f_{2}\left(s_{i}\right)$} & 0.3338 & 0.2626 & -0.6215 & 0.0274 & -4.0133 \\
\hline & $(0.5131)$ & $(0.5663)$ & $(3.1485)$ & $(0.5170)$ & $(3.6714)$ \\
\hline \multirow{2}{*}{$\mathrm{EMR} \& \mathrm{CPOE} \times f_{3}\left(s_{i}\right)$} & -3.5100 & -1.3254 & -3.5363 & -0.1198 & 13.9576 \\
\hline & $(2.2881)$ & $(2.2538)$ & (11.5891) & $(2.0027)$ & (15.8886) \\
\hline \multirow{2}{*}{$\mathrm{EMR} \& \mathrm{CPOE} \times f_{4}\left(s_{i}\right)$} & $6.8087^{*}$ & 1.7570 & 9.2619 & 0.1539 & -12.3796 \\
\hline & $(3.0301)$ & $(2.7103)$ & $(13.7843)$ & $(2.5507)$ & (19.3525) \\
\hline Observations & $2,167,654$ & $2,399,648$ & $1,004,402$ & 878,547 & 35,770 \\
\hline
\end{tabular}

${ }^{\dagger}$ includes non-STEMIs and STEMIs with secondary CHF or CA diagnoses.

¥ includes STEMI without secondary diagnoses of CHF or CA.

*Denotes significance at $p<0.05$ and ${ }^{* *}$ at $p<0.01$ and ${ }^{* * *}$ at $p<.001$

Key parameters from 10 separate regressions estimated by OLS with SEs clustered by hospital. $f_{1}\left(s_{i}\right), f_{2}\left(s_{i}\right)$, and $f_{3}\left(s_{i}\right)$ are a fourth-order cubic spline of severity. 
Table 7: FE estimates of health IT, coordination, and information management on mortality

\begin{tabular}{|c|c|c|c|c|c|}
\hline & $\mathrm{PN}$ & $\mathrm{CHF}$ & $\mathrm{CA}$ & $\mathrm{AMI}^{\dagger}$ & STEMI ${ }^{\ddagger}$ \\
\hline \multirow[t]{2}{*}{$s^{c}$} & $1.0876^{* * *}$ & $1.0595^{* * *}$ & $1.0717^{* * *}$ & $1.0474^{* * *}$ & $0.8945^{* * *}$ \\
\hline & $(0.0028)$ & $(0.0024)$ & $(0.0049)$ & $(0.0039)$ & $(0.0213)$ \\
\hline \multirow[t]{4}{*}{$s^{m}$} & $1.0163^{* * *}$ & $1.0177^{* * *}$ & $1.0100 * * *$ & $1.0071^{* * *}$ & $0.9689^{* * *}$ \\
\hline & $(0.0025)$ & $(0.0019)$ & $(0.0050)$ & $(0.0024)$ & $(0.0176)$ \\
\hline & $1.0118^{* * *}$ & $1.0084^{* * *}$ & $1.0087^{* * *}$ & $1.0127 * * *$ & $0.9521^{* * *}$ \\
\hline & $(0.0012)$ & $(0.0015)$ & $(0.0044)$ & $(0.0019)$ & $(0.0160)$ \\
\hline \multirow[t]{2}{*}{$E M R \& C P O E$} & $0.0097^{* * *}$ & 0.0018 & 0.0021 & $0.0137^{*}$ & 0.0636 \\
\hline & $(0.0028)$ & $(0.0022)$ & $(0.0016)$ & $(0.0050)$ & $(0.0423)$ \\
\hline \multirow{2}{*}{$(E M R \& C P O E) \times s^{c}$} & $-0.1193^{* * *}$ & 0.0146 & -0.0199 & $-0.0948^{*}$ & -0.2624 \\
\hline & $(0.0365)$ & $(0.0289)$ & $(0.0682)$ & $(0.0408)$ & $(0.2113)$ \\
\hline \multirow{2}{*}{$(E M R \& C P O E) \times s^{m}$} & $-0.0992^{* *}$ & $-0.0646^{* *}$ & $-0.1641^{*}$ & -0.0514 & -0.1347 \\
\hline & $(0.0341)$ & $(0.0241)$ & $(0.0679)$ & $(0.0296)$ & $(0.1154)$ \\
\hline \multirow{2}{*}{$(E M R \& C P O E) \times s^{o}$} & $-0.0611^{* * *}$ & -0.0289 & $-0.1417^{*}$ & -0.0128 & -0.0371 \\
\hline & $(0.0182)$ & $(0.0169)$ & $(0.0636)$ & $(0.0217)$ & $(0.1337)$ \\
\hline Observations & $2,167,654$ & $2,399,648$ & $1,004,402$ & 878,547 & 35,770 \\
\hline
\end{tabular}

$\dagger$ includes non-STEMIs and STEMIs with secondary CHF or CA diagnoses.

$\ddagger$ includes STEMI without secondary diagnoses of CHF or CA.

*Denotes significance at $p<0.05$ and $* *$ at $p<0.01$ and $* * *$ at $p<.001$

Key parameters from 5 regressions estimated by OLS including hospital and time indicators. Bootstrapped SEs clustered by hospital. $s^{c}, s^{m}$, and $s^{c}$ defined in text. 
Table 8: FE estimates of health IT and the role of learning, innovation, and adding leads

\begin{tabular}{|c|c|c|c|c|c|}
\hline & $\mathrm{PN}$ & $\mathrm{CHF}$ & $\mathrm{CA}$ & $\mathrm{AMI}^{\dagger}$ & STEMI $^{\ddagger}$ \\
\hline \multicolumn{6}{|c|}{ Learning effects (A) } \\
\hline \multirow[t]{2}{*}{$E M R \& C P O E$} & 0.0052 & 0.0033 & $0.0043^{*}$ & -0.0020 & 0.0407 \\
\hline & $(0.0037)$ & $(0.0037)$ & $(0.0020)$ & $(0.006)$ & $(0.083)$ \\
\hline \multirow{2}{*}{$(E M R \& C P O E)_{t-2}$} & 0.0077 & 0.0057 & -0.0004 & -0.0145 & -0.1012 \\
\hline & $(0.0042)$ & $(0.0040)$ & $(0.0023)$ & $(0.024)$ & $(0.210)$ \\
\hline \multirow{2}{*}{$(E M R \& C P O E) \times s_{i}$} & $-0.0665^{* *}$ & -0.0307 & $-0.1668^{* *}$ & 0.0058 & 0.0482 \\
\hline & $(0.0222)$ & $(0.0214)$ & $(0.0606)$ & $(0.006)$ & $(0.100)$ \\
\hline \multirow{2}{*}{$(E M R) \& C P O E)_{t-2} \times s_{i}$} & -0.0434 & -0.0274 & 0.0330 & -0.0272 & -0.0367 \\
\hline & $(0.0290)$ & $(0.0253)$ & $(0.0730)$ & $(0.029)$ & $(0.255)$ \\
\hline \multicolumn{6}{|c|}{ Innovation effects (B) } \\
\hline \multirow{2}{*}{$E M R \& C P O E$} & 0.0055 & 0.0043 & 0.0037 & 0.0207 & 0.0277 \\
\hline & $(0.0037)$ & $(0.0035)$ & $(0.0021)$ & $(0.008)$ & $(0.070)$ \\
\hline \multirow{2}{*}{$(E M R \& C P O E) \times\left(\right.$ Adopt post $\left.{ }^{\prime} 04\right)$} & 0.0068 & 0.0032 & 0.0007 & -0.0123 & 0.0557 \\
\hline & $(0.0041)$ & $(0.0039)$ & $(0.0022)$ & $(0.008)$ & $(0.056)$ \\
\hline \multirow{2}{*}{$(E M R \& C P O E) \times s_{i}$} & $-0.0804^{* *}$ & -0.0318 & $-0.1543^{* *}$ & $-0.0452^{* *}$ & -0.1731 \\
\hline & $(0.0219)$ & $(0.0189)$ & $(0.0595)$ & $(0.016)$ & $(0.129)$ \\
\hline \multirow{2}{*}{$(E M R \& C P O E) \times\left(\right.$ Adopt post $\left.{ }^{\prime} 04\right) \times s_{i}$} & -0.0158 & -0.0217 & 0.0105 & -0.0339 & -0.0487 \\
\hline & $(0.0236)$ & $(0.0208)$ & $(0.0606)$ & $(0.034)$ & $(0.265)$ \\
\hline \multicolumn{6}{|c|}{ Incorporating leads of technology adoption (C) } \\
\hline$E M R \& C P O E$ & $0.0117^{* *}$ & $0.0126^{* *}$ & $0.0060^{*}$ & -0.0003 & 0.0649 \\
\hline & $(0.0043)$ & $(0.0038)$ & $(0.0027)$ & $(0.008)$ & $(0.093)$ \\
\hline \multirow{2}{*}{$(E M R \& C P O E) \times s_{i}$} & $-0.1430^{* *}$ & $-0.0936^{* *}$ & $-0.2100^{* *}$ & -0.0013 & -0.3180 \\
\hline & $(0.0192)$ & $(0.0188)$ & $(0.0551)$ & $(0.029)$ & $(0.237)$ \\
\hline \multirow[t]{4}{*}{$(E M R \& C P O E)_{t+1}$} & -0.0046 & 0.0041 & -0.0014 & 0.0019 & 0.0419 \\
\hline & $(0.0043)$ & $(0.0035)$ & $(0.0025)$ & $(0.005)$ & $(0.026)$ \\
\hline & 0.0068 & -0.0082 & 0.0045 & 0.0012 & -0.0091 \\
\hline & $(0.0074)$ & $(0.0051)$ & $(0.0047)$ & $(0.005)$ & $(0.029)$ \\
\hline \multicolumn{6}{|c|}{ Incorporating leads of technology adoption with severity interactions (D) } \\
\hline \multirow[t]{2}{*}{$E M R \& C P O E$} & 0.0010 & -0.0073 & 0.0030 & 0.0030 & 0.0289 \\
\hline & $(0.0056)$ & $(0.0053)$ & $(0.0034)$ & $(0.0084)$ & $(0.0582)$ \\
\hline \multirow[t]{2}{*}{$(E M R \& C P O E) \times s_{i}$} & -0.0206 & -0.0053 & -0.0762 & -0.0114 & -0.2010 \\
\hline & $(0.0294)$ & $(0.0331)$ & $(0.0823)$ & $(0.0333)$ & $(0.1446)$ \\
\hline \multirow[t]{2}{*}{ 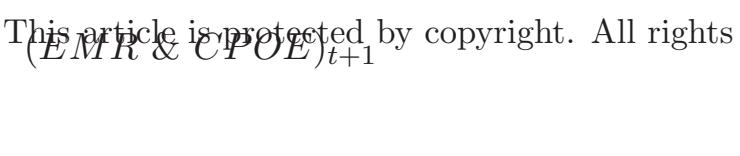 } & respryedity & 0.0071 & 0.0057 & 0.0021 & 0.0682 \\
\hline & $(0.0076)$ & $(0.0049)$ & $(0.0030)$ & $(0.0081)$ & $(0.0583)$ \\
\hline$(E M R \& C P O E)_{t+1} \times s_{i}$ & -0.0662 & -0.0471 & -0.1141 & 0.0018 & -0.1029 \\
\hline
\end{tabular}


Table 9: *

Table A1: Effect of EMR and CPOE on inpatient outcomes without hospital FE

\begin{tabular}{|c|c|c|c|c|c|}
\hline & PN & $\mathrm{CHF}$ & $\mathrm{CA}$ & $\mathrm{AMI}^{\dagger}$ & STEMI $^{\ddagger}$ \\
\hline \multicolumn{6}{|c|}{ Mortality, 60-days (A) } \\
\hline \multirow[t]{2}{*}{ EMR \& CPOE } & $-0.005^{*}$ & -0.002 & -0.002 & -0.0056 & -0.0022 \\
\hline & $(0.002)$ & $(0.002)$ & $(0.001)$ & $(0.0035)$ & $(0.0146)$ \\
\hline \multicolumn{6}{|c|}{ Length of stay (B) } \\
\hline EMR \& CPOE & $-0.210 * *$ & -0.043 & -0.007 & -0.0661 & 0.2089 \\
\hline & $(0.072)$ & $(0.077)$ & $(0.078)$ & $(0.0910)$ & $(0.1864)$ \\
\hline \multicolumn{6}{|c|}{ Readmissions, 30-days (C) } \\
\hline EMR \& CPOE & -0.001 & 0.000 & -0.002 & -0.0048 & 0.0035 \\
\hline & $(0.002)$ & $(0.003)$ & $(0.004)$ & $(0.0043)$ & $(0.0101)$ \\
\hline Observations & $2,167,654$ & $2,399,648$ & $1,004,402$ & 878,547 & 35,770 \\
\hline
\end{tabular}

includes non-STEMIs and STEMIs with secondary CHF or CA diagnoses.

includes STEMI without secondary diagnoses of CHF or CA.

*Denotes significance at $p<0.05$ and ${ }^{* *}$ at $p<0.01$

Key parameters from 12 separate regressions estimated by OLS with

errors clustered by hospital. Regressions each include the following demographic controls: female, white, female $\times$ white, age, age2, age3,

white $\times$ age, female $\times$ age. Diagnosis-based controls include: weighted count of ADGs, weighted count of ADGs for prior admission (conditional upon an admission within the past 6 months), primary diagnosis subcategory indicators (4-digit ICD-9 for AMI, CA, and CHF, and 3-digit for PN), and secondary diagnosis indicators (AMI, PN, CA, CHF, diabetes, renal failure). Admission type indicators included: emergent, urgent, and transfer. Hospital controls include adjusted admissions and multi-hospital system membership. 
Table 10: *

Table A2: Parameter estimates for severity spline terms in Table 6, Panel B.

\begin{tabular}{cccccc}
\hline \hline$+f_{1}\left(s_{i}\right)$ & $\mathrm{PN}$ & $\mathrm{CHF}$ & $\mathrm{CA}$ & $\mathrm{AMI}^{\dagger}$ & $\mathrm{STEMI}^{\ddagger}$ \\
& $0.7087^{* * *}$ & $0.6816^{* * *}$ & $0.2491^{* * *}$ & $0.6848^{* * *}$ & $1.0198^{* * *}$ \\
$f_{2}\left(s_{i}\right)$ & $(0.0136)$ & $(0.0145)$ & $(0.0414)$ & $(0.0139)$ & $(0.0778)$ \\
& $0.9667^{* * *}$ & $1.0809^{* * *}$ & $7.1977^{* * *}$ & $1.1856^{* * *}$ & 1.261021 \\
$f_{3}\left(s_{i}\right)$ & $(0.1231)$ & $(0.1382)$ & $(0.8089)$ & $(0.1396)$ & $(0.6919)$ \\
& $-2.0349^{* * *}$ & $-2.1906^{* * *}$ & $-17.8509^{* * *}$ & $-1.8607^{* * *}$ & $-7.3721^{*}$ \\
$f_{4}\left(s_{i}\right)$ & $(0.5455)$ & $(0.5515)$ & $(2.8275)$ & $(0.5254)$ & $(3.1317)$ \\
& 1.0876 & 1.1886 & $12.9008^{* * *}$ & -0.3123 & $9.7380^{*}$ \\
\hline Observations & $2,167,654$ & $2,399,648$ & $1,004,402$ & 878,547 & 35,770 \\
\hline \hline
\end{tabular}

† includes non-STEMIs and STEMIs with secondary CHF or CA diagnoses.

* includes STEMI without secondary diagnoses of CHF or CA.

*Denotes significance at $p<0.05$ and ${ }^{* *}$ at $p<0.01$ and $* * *$ at $p<.001$

Key parameters from 10 regressions estimated by OLS with SEs clustered by hospital.

Difference-in-differences identification. The terms $f_{1}\left(s_{i}\right), f_{2}\left(s_{i}\right)$, and $f_{3}\left(s_{i}\right)$ are generated by a fourth-order cubic spline of severity.

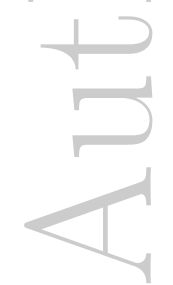

This article is protected by copyright. All rights reserved. 
Table 11: *

Table A3: Robustness test for FE estimates of EMR \& CPOE adoption on 60-day mortality allowing for heterogeneous effects in patient severity

\begin{tabular}{|c|c|c|c|c|c|}
\hline & $\mathrm{PN}$ & $\mathrm{CHF}$ & $\mathrm{CA}$ & $\mathrm{AMI}^{\dagger}$ & STEMI $^{\ddagger}$ \\
\hline \multirow[t]{2}{*}{$s \quad D$} & $0.8592^{* * *}$ & $0.8521^{* * *}$ & $0.8185^{* * *}$ & $0.9253^{* * *}$ & $0.8332^{* * *}$ \\
\hline & $(0.0068)$ & $(0.0077)$ & $(0.0222)$ & $(0.0081)$ & $(0.0268)$ \\
\hline \multirow[t]{2}{*}{ EMR \& CPOE } & 0.0046 & 0.0050 & $0.0056^{*}$ & 0.0044 & 0.0245 \\
\hline & $(0.0038)$ & $(0.0035)$ & $(0.0028)$ & $(0.0065)$ & $(0.0407)$ \\
\hline \multirow[t]{2}{*}{$\mathrm{EMR} \& \mathrm{CPOE} \times s$} & $-0.0804^{* * *}$ & $-0.0392^{* *}$ & $-0.1514^{* *}$ & -0.0322 & -0.1665 \\
\hline & $(0.0173)$ & $(0.0138)$ & $(0.0401)$ & $(0.0184)$ & $(0.0849)$ \\
\hline \multirow{2}{*}{ EMR \& CPOE $\times$ ITage } & 0.0043 & $0.0074^{* * *}$ & 0.0005 & 0.0051 & -0.0113 \\
\hline & $(0.0026)$ & $(0.0022)$ & $(0.0014)$ & $(0.0036)$ & $(0.0305)$ \\
\hline \multirow{2}{*}{ EMR \& CPOE $\times s \times$ ITage } & $-0.0235^{*}$ & $-0.0307^{* * *}$ & 0.0004 & $-0.0388 * * *$ & 0.0221 \\
\hline & $(0.0118)$ & $(0.0092)$ & $(0.0283)$ & $(0.0121)$ & $(0.0642)$ \\
\hline \multirow{2}{*}{ Ever adopt $\times$ time } & $0.0027^{*}$ & -0.0002 & 0.0003 & 0.0038 & 0.0214 \\
\hline & $(0.0012)$ & $(0.0012)$ & $(0.0009)$ & $(0.0021)$ & $(0.0118)$ \\
\hline Observations & $2,167,654$ & $2,399,648$ & $1,004,402$ & 878,547 & 35,770 \\
\hline
\end{tabular}

$\dagger$ includes non-STEMIs and STEMIs with secondary CHF or CA diagnoses.

$\ddagger$ includes STEMI without secondary diagnoses of CHF or CA.

*Denotes significance at $p<0.05$ and $* *$ at $p<0.01$ and $* * *$ at $p<.001$

Key parameters from 10 separate regressions estimated by FE with SEs clustered by hospital. $f_{1}\left(s_{i}\right), f_{2}\left(s_{i}\right)$, and $f_{3}\left(s_{i}\right)$ are a fourth-order cubic spline of severity. 
Table 12: *

Table A4: Ro-

bustness test for FE estimates of health IT, coordination, and information management on mortality

\begin{tabular}{|c|c|c|c|c|c|}
\hline & $\mathrm{PN}$ & $\mathrm{CHF}$ & $\mathrm{CA}$ & $\mathrm{AMI}^{\dagger}$ & STEMI ${ }^{\ddagger}$ \\
\hline \multirow[t]{2}{*}{$s^{c}$} & $0.8909^{* * *}$ & $0.9877^{* * *}$ & $0.9423^{* * *}$ & $1.0033^{* * *}$ & $0.7917^{* * *}$ \\
\hline & $(0.0135)$ & $(0.0128)$ & $(0.0239)$ & $(0.0167)$ & $(0.0395)$ \\
\hline \multirow[t]{2}{*}{$s^{m}$} & $0.7311^{* * *}$ & $0.7069^{* * *}$ & $0.7610^{* * *}$ & $0.7976^{* * *}$ & $0.8238^{* * *}$ \\
\hline & $(0.0184)$ & $(0.0127)$ & $(0.0325)$ & $(0.0173)$ & $(0.0522)$ \\
\hline \multirow[t]{2}{*}{$s^{o}$} & $0.9295^{* * *}$ & $0.9967 * * *$ & $0.8972^{* * *}$ & $1.0108^{* * *}$ & $0.9121^{* * *}$ \\
\hline & $(0.0067)$ & $(0.0099)$ & $(0.0228)$ & $(0.0080)$ & $(0.0426)$ \\
\hline \multirow{2}{*}{$E M R \& C P O E$} & -0.0003 & -0.0006 & 0.0010 & 0.0082 & 0.0202 \\
\hline & $(0.0039)$ & $(0.0040)$ & $(0.0028)$ & $(0.0078)$ & $(0.0511)$ \\
\hline \multirow{2}{*}{$(E M R \& C P O E) \times s^{c}$} & -0.0889 & 0.0697 & 0.0604 & -0.0913 & -0.2626 \\
\hline & $(0.0407)$ & $(0.0400)$ & $(0.0805)$ & $(0.0543)$ & $(0.2277)$ \\
\hline \multirow{2}{*}{$(E M R \& C P O E) \times s^{m}$} & $-0.1212^{* * *}$ & $-0.0673^{* * *}$ & $-0.1705^{* *}$ & -0.0245 & -0.1954 \\
\hline & $(0.0361)$ & $(0.0212)$ & $(0.0610)$ & $(0.0332)$ & $(0.1185)$ \\
\hline \multirow{2}{*}{$(E M R \& C P O E) \times s^{o}$} & -0.0231 & -0.0262 & $-0.1698^{*}$ & -0.0115 & -0.0322 \\
\hline & $(0.0228)$ & $(0.0252)$ & $(0.0698)$ & $(0.0296)$ & $(0.1763)$ \\
\hline \multirow{2}{*}{$E M R \& C P O E \times I T a g e$} & 0.0046 & 0.0045 & 0.0020 & -0.0015 & -0.0047 \\
\hline & $(0.0027)$ & $(0.0025)$ & $(0.0017)$ & $(0.0051)$ & $(0.0373)$ \\
\hline \multirow{2}{*}{$(E M R \& C P O E) \times s^{c} \times$ ITage } & -0.0284 & $-0.0591^{*}$ & -0.0944 & 0.0033 & 0.0370 \\
\hline & $(0.0271)$ & $(0.0277)$ & $(0.0667)$ & $(0.0413)$ & $(0.1683)$ \\
\hline \multirow{2}{*}{$(E M R \& C P O E) \times s^{m} \times$ ITage } & 0.0100 & -0.0225 & 0.0083 & $-0.0614^{* *}$ & 0.0409 \\
\hline & $(0.0249)$ & $(0.0161)$ & $(0.0396)$ & $(0.0214)$ & $(0.1004)$ \\
\hline \multirow{2}{*}{$(E M R \& C P O E) \times s^{o} \times$ ITage } & $-0.0370^{*}$ & 0.0041 & 0.0382 & -0.0079 & -0.0394 \\
\hline & $(0.0157)$ & $(0.0182)$ & $(0.0477)$ & $(0.0215)$ & $(0.1299)$ \\
\hline \multirow{2}{*}{ Ever adopt $\times$ time } & $0.0034^{* *}$ & 0.0002 & 0.0004 & 0.0040 & 0.0218 \\
\hline & $(0.0012)$ & $(0.0012)$ & $(0.0009)$ & $(0.0020)$ & $(0.0118)$ \\
\hline Observations & $2,167,654$ & $2,399,648$ & $1,004,402$ & 878,547 & 35,770 \\
\hline
\end{tabular}

$\dagger$ includes non-STEMIs and STEMIs with secondary CHF or CA diagnoses.

$\ddagger$ includes STEMI without secondary diagnoses of CHF or CA.

*Denotes significance at $p<0.05$ and ** at $p<0.01$ and $* * *$ at $p<.001$ This article is protected by copyright. All rights reserved.

Key parameters from 5 regressions estimated by OLS including hospital and

time indicators. Bootstrapped SEs clustered by hospital. $s^{c}, s^{m}$, and $s^{c}$ defined in text. 
Table 13: *

Table A5: Regression of Severity on Health IT Adoption

\begin{tabular}{|c|c|c|c|c|c|}
\hline \multirow{5}{*}{ EMR \& CPOE } & $\mathrm{PN}$ & $\mathrm{CHF}$ & $\mathrm{CA}$ & $\mathrm{AMI}^{\dagger}$ & STEMI $^{\ddagger}$ \\
\hline & 0.0013 & 0.0026 & 0.0004 & -0.0023 & 0.0017 \\
\hline & $(0.0009)$ & $(0.0100)$ & $(0.0005)$ & $(0.0016)$ & $(0.0070)$ \\
\hline & $-0.0021^{*}$ & $-0.0024^{*}$ & -0.0009 & -0.0032 & 0.0081 \\
\hline & $(0.0010)$ & $(0.0011)$ & $(0.0005)$ & $(0.0018)$ & $(0.0087)$ \\
\hline Scale (beds) & 0.0000 & 0.0000 & 0.0000 & 0.0000 & 0.0000 \\
\hline & $(0.0000)$ & $(0.0000)$ & $(0.0000)$ & $(0.0000)$ & $(0.0000)$ \\
\hline COTH Member & -0.0019 & $-0.0037^{*}$ & -0.0008 & $-0.0064^{*}$ & $-0.0276^{*}$ \\
\hline & $(0.0021)$ & $(0.0015)$ & $(0.0008)$ & $(0.0026)$ & $(0.0119)$ \\
\hline Observations & $2,167,654$ & $2,399,648$ & $1,004,402$ & 878,547 & 35,770 \\
\hline
\end{tabular}

includes non-STEMIs and STEMIs with secondary CHF or CA diagnoses.

¥ includes STEMI without secondary diagnoses of CHF or CA.

${ }^{*}$ Denotes significance at $p<0.05$ and ${ }^{* *}$ at $p<0.01$ and ${ }^{* * *}$ at $p<.001$

Key parameters from 5 regressions with SEs clustered by hospital.

Difference-in-differences identification.

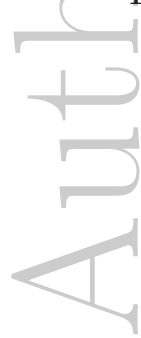

This article is protected by copyright. All rights reserved. 
Table 14: *

Table A6: Explanation of Acronyms

$\begin{array}{ll}\text { Acronyms } & \text { Explanation } \\ \text { EMR } & \text { Electronic Medical Record } \\ \text { CPOE } & \text { Computerized Provider Order Entry } \\ \text { PACS } & \text { Electronic Medication Administration Record } \\ \text { AMI* } & \text { Acute Myocardial Infarction Archiving Communications Systems } \\ \text { STEMI* } & \text { ST-elevated Myocardial Infarction } \\ \text { CHF } & \text { Congestive Heart Failure } \\ \text { CA } & \text { Coronary Atherosclerosis } \\ \text { PN } & \text { Pneumonia } \\ \text { IM } & \text { Information Management } \\ \text { FFS } & \text { Fee-for-service }\end{array}$

*We use STEMI to refer to ST-elevated MIs with no secondary diagnosis

of either CHF, CA, or PN and AMI to refer to all other MIs.

This article is protected by copyright. All rights reserved. 